\title{
Interannual and Decadal Variability in an Intermediate Coupled Model of the Pacific Region*
}

\author{
Amy Solomon And Julian P. MCCREARy, JR. \\ International Pacific Research Center, University of Hawaii at Manoa, Honolulu, Hawaii \\ RICHARD KLEEMAN \\ Courant Institute, New York, New York \\ BARRY A. KLINGER + \\ Oceanographic Center, Nova Southeastern University, Dania Beach, Florida
}

(Manuscript received 4 October 2001, in final form 7 August 2002)

\begin{abstract}
Processes that cause decadal variability in an intermediate coupled ocean-atmosphere model of the Pacific basin, both at northern midlatitudes and in the Tropics, are studied. The model's ocean component is a variabletemperature 31/2-layer system. Its atmospheric component consists of two basic parts: an empirical model, constructed from patterns obtained by the singular value decomposition (SVD) statistical technique that determines wind stress anomalies from model sea surface temperature (SST), and a simple representation of the planetary boundary layer to calculate the surface heat flux anomalies. A third part specifies stochastic wind stress forcing from observed variability. In addition, the model is specifically designed to separate tropical and extratropical interactions, such that the Tropics can force the extratropics through the atmosphere but the extratropics can only feed back to the Tropics through the ocean.

Solutions develop two types of oscillations: an ENSO-like interannual mode and a decadal mode. As in many models of ENSO, the interannual mode is driven by positive, ocean-atmosphere feedbacks near the equator, and time-delayed negative feedback is provided by off-equatorial Rossby waves. For parameter choices that amplify midlatitude coupling by $30 \%\left(\phi_{o}=1.3\right)$, a self-sustained decadal oscillation develops in the North Pacific without any tropical interactions. Diagnostic analyses show that it is maintained by ocean-to-atmosphere feedbacks in the northwest and subtropical northeast Pacific, and by atmospheric teleconnections from those regions to the northeast ocean. For weaker coupling $\left(\phi_{o}=1.2\right)$, the decadal mode is damped. In this case, the mode can be sustained by atmospheric teleconnections from the Tropics associated with the interannual mode, but not by extratropical stochastic forcing. Although including stochastic forcing does generate variability at decadal timescales, a distinct decadal spectral peak only exists when the decadal mode is active.

Decadal variability is carried to the equator by variations in the transport, rather than temperature, of the North Pacific subtropical cell. These variations modulate near-equatorial SST by altering the amount of cool, thermocline water that upwells in the eastern equatorial Pacific, which in turn feeds back to the interannual mode.
\end{abstract}

\section{Introduction}

Observational studies of decadal variability in the $\mathrm{Pa}$ cific sector suggest that North Pacific decadal variability

\footnotetext{
* School of Ocean and Earth Sciences and Technology, University of Hawaii at Manoa, Contribution Number 6067 and International Pacific Research Center Contribution Number 179.

+ Current affiliation: George Mason University, Fairfax, Virginia, and the Center for Ocean-Land-Atmosphere Studies, Calverton, Maryland.
}

Corresponding author address: Dr. Amy B. Solomon, CIRES/Climate Diagnostics Center, University of Colorado, 216 UCB, Boulder, CO 80309-0216.

E-mail: amy@cdc.noaa.gov
(PDV) and ENSO decadal variability (EDV) are related (Trenberth 1990; Latif et al. 1997; Kleeman and Power 1999). For example, the results of Wang (1995) suggest that concurrent with the 1970s "climate shift" in the North Pacific (Nitta and Yamada 1989; Trenberth 1990) there was an interdecadal change in the background state of the tropical Pacific that changed the onset of ENSO events, limiting predictability in coupled models (Ji et al. 1996). There is evidence that these conditions form part of a large-amplitude decadal variation in Pacific sea surface temperature (SST) extending back to the 1950s (Latif et al. 1997). At the present time, there is considerable debate as to the causes of both PDV and EDV. Are they generated at midlatitudes or the Tropics? Are they separate phenomena, or dynamically linked? 


\section{a. North Pacific decadal variability}

One hypothesis for PDV is that it results from a selfsustained coupled mode of oscillation in the subtropics and midlatitudes. Such modes require a systematic relationship between oceanic and atmospheric variables. In the time-delay oscillator, for example, they result from ocean-to-atmosphere positive feedback in one region (region 1) with atmospheric teleconnections to another region (region 2); subsequently, atmosphere-toocean interactions in region 2 lead to negative feedback in region 1 via oceanic teleconnections, typically by the propagation of Rossby waves.

A mode of this sort is present in the solutions to a coupled general circulation model (GCM) reported by Latif and Barnett $(1994,1996)$. In these solutions, the mode appears to be generated by ocean-to-atmosphere feedback in the western North Pacific, which remotely influences the Aleutian low pressure system via atmospheric teleconnections. Anomalous winds associated with these pressure variations then generate oceanic Rossby waves that slowly propagate across the basin, eventually providing the negative feedback necessary to reverse the oscillation (Neelin and Weng 1999; Muennich et al. 1998). Latif and Barnett $(1994,1996)$ and Kleeman et al. (1999, hereafter KMK), who used an intermediate coupled model, concluded that positive feedbacks due to both wind stress and heat flux anomalies were important for the mode's excitation, whereas subtropical gyre adjustment and advection (both of which have decadal timescales) were likely responsible for determining its period. Pierce et al. (2000b), using a coupled GCM, concluded that coupled ocean-atmosphere modes were important for determining the strength and frequency of decadal variability in the $\mathrm{Ku}$ roshio Extension region.

Such relationships have so far been difficult to detect observationally in the North Pacific, due to the shortness of the available records and to the presence of largeamplitude, high-frequency (periods less than $1 \mathrm{yr}$ ) atmospheric variability. Indeed, a number of studies suggest that at high frequencies the North Pacific is predominantly forced by the atmosphere; they include analyses based on lagged cross correlations between observed SST and atmospheric variables (e.g., Davis 1976; Frankignoul 1985; Deser and Timlin 1997) and modeling studies using thermodynamic models, both 1D systems (e.g., Hasselmann 1976; Barsugli and Battisti 1998; Frankignoul 1999) and AGCMs coupled to mixed-layer oceans (e.g., Bladé 1997). As discussed next, however, there are studies of low-frequency variability that support various aspects associated with coupled modes.

Several studies point toward the existence of oceanto-atmosphere coupling in one region with atmospheric teleconnections to another. Nakamura and Izumi (2002) found that warm interannual-to-decadal atmospheric temperature anomalies at the top of the planetary bound- ary layer (PBL) in the northwest Pacific (Kuroshio Extension region) are associated with enhanced storm track activity and a weakening of the Aleutian low. Nakamura et al. (1997) and Nakamura and Yamagata (1999) reported two modes of North Pacific decadal variability based on an empirical orthogonal function (EOF) analysis of low-pass SST data in the northwest Pacific. Atmospheric and SST fields throughout the basin were then obtained by regression with the time series for each EOF. The SST field associated with the first EOF (EOF1) was confined to midlatitudes, with most of its amplitude centered on the subarctic front. In contrast, the SST pattern corresponding to the second EOF (EOF2) extended over much of the basin; in northern subtropics and midlatitudes, it had a distinctive dipolelike structure, with anomalies of opposite sign on either side of the subtropical front, and it also had significant amplitude throughout the Tropics in both hemispheres. To investigate where the atmospheric circulations associated with each mode were forced, Nakamura and Yamagata (1999) determined the wave-activity flux, $W$, of stationary Rossby waves on the climatological mean flow based on 500-hPa geopotential height anomalies. For EOF1, $W$ was divergent in the central North Pacific in the latitudinal band of the storm track and the subarctic front, whereas for EOF2 it was divergent in the eastern North Pacific above the subtropical front (see Fig. 4 of Nakamura and Yamagata 1999), indicative of external forcing by SST anomalies in each region. In both cases, the predominant direction of the flux vectors was from the divergent regions into the northeast $\mathrm{Pa}$ cific, suggestive of atmospheric teleconnections into that area.

Recently, Nonaka and Xie (2003) reported evidence of direct ocean-to-atmosphere interaction in the region of the Kuroshio, both south of Japan and its extension into the North Pacific. The authors analyzed SST and wind stress data from satellite microwave measurements, finding that increased (reduced) wind speeds are associated with warm (cold) SST anomalies (SSTAs), that is, the two fields are positively correlated. They concluded that warm SSTAs strengthen the surface winds by reducing the static stability of the PBL, and vice versa. Specifically, an increase in SST intensifies vertical turbulence, thereby mixing stronger winds from aloft to the sea surface. The authors note that this result contrasts with the negative SST-wind correlations that are often observed in regions of weak currents, such as in the North Pacific south of the Aleutian low, the negative relationship considered to be indicative of atmosphere-to-ocean forcing. It is noteworthy that a similar mechanism has been invoked to account for positive SST-wind correlations in the Southern Ocean (O'Neill and Chelton 2002, manuscript submitted to J. Climate).

There is also observational support that remotely forced oceanic Rossby waves account for a significant amount of decadal variations in the Kuroshio Extension region (Deser et al. 1999; Miller and Schneider 2000), 
since they cannot be explained by contemporaneous local forcing (Xie et al. 2000). Moreover, Schneider and Miller (2001) used a simple, linear, Rossby wave equation forced by observed wind stress curl to demonstrate that SSTs in the western North Pacific can be skillfully predicted at lead times of up to $3 \mathrm{yr}$. The mechanisms responsible for generating the Rossby waves is not yet known.

The lack of strong observational support for a welldefined decadal oscillation in the North Pacific motivated Barnett et al. (1999) and Schneider et al. (2002) to conclude that the decadal variability in their coupled GCM was generated by stochastic wind stress variability, rather than by a self-sustained coupled mode. Weng and Neelin (1999) came to a similar conclusion based on solutions to their intermediate midlatitude coupled model. It is not yet clear, however, just how effective stochastic forcing is in driving the large-scale changes noted previously.

\section{b. ENSO decadal variability}

Several mechanisms have been proposed for the generation of EDV. They include nonlinearities in oceanatmosphere coupling within the Tropics (e.g., Timmermann and Jin 2002), ENSO-like ocean-to-atmosphere positive feedback with time-delayed negative feedback provided by subtropical Rossby waves (e.g., Knutson and Manabe 1998; Yukimoto et al. 2000), atmospheric teleconnections from midlatitudes to the Tropics (e.g., Barnett et al. 1999; Pierce et al. 2000a), and oceanic teleconnections from the subtropics to the equator by variations in western boundary current transports (Lysne et al. 1997).

Two other oceanic mechanisms involve variations in the temperature ( $\mathrm{Gu}$ and Philander 1997) or transport (KMK) of the Pacific subtropical cells (STCs). The STCs are shallow $(z \lesssim-500 \mathrm{~m})$ meridional circulation cells in which water flows out of the Tropics within the surface layer, subducts in the subtropics, flows equatorward within the thermocline, and upwells in the eastern equatorial ocean (Bryan 1991, see his Fig. 2; McCreary and Lu 1994; Liu et al. 1994; Blanke and Raynaud 1997; Rothstein et al. 1998; Lu et al. 1998).

$\mathrm{Gu}$ and Philander (1997) hypothesized that North Pacific SST anomalies are subducted into the thermocline to join the north STC, and are subsequently advected to the equatorial Pacific with a time lag of the order of a decade, thereby providing a delayed negative feedback (the $\overline{\mathbf{v}} T^{\prime}$ hypothesis). This idea received observational support from Deser et al. (1996), who were able to follow the equatorward movement of a subsurface anomaly for some distance. Recent solutions using oceanic GCMs, however, suggest that most of this subtropical signal recirculates in the subtropical gyre, with little ever reaching the equator (Schneider et al. 1999; Nonaka et al. 2000). As proposed by Gu and Philander (1997), then, the STC pathway may not provide a suf- ficiently strong interaction to account for ENSO decadal variability.

KMK used an intermediate coupled model to study PDV and EDV. Their solutions developed two modes of oscillation: an ENSO-like interannual mode ( $\sim 4 \mathrm{yr})$ and a decadal one $(\sim 13 \mathrm{yr})$. The decadal mode was generated in northern midlatitudes, and was similar in structure to the Latif and Barnett (1994) decadal mode. It was found to influence the equatorial cold tongue by altering the transport of the ocean model's northern STC, thereby modulating ENSO on decadal timescales ( $\overline{\mathbf{v}} T^{\prime}$ hypothesis). The STC transport was determined largely by the Ekman transport across the edge of the tropical warm pool, thereby linking subtropical wind variability to equatorial SST anomalies. These ideas are supported by the modeling study of Nonaka et al. (2002); in their wind-driven solutions, there is a close connection between equatorial SST anomalies and subsurface heat transports across $11^{\circ} \mathrm{S}$ and $15^{\circ} \mathrm{N}$ at decadal timescales. They are also supported by the observational study of McPhaden and Zhang (2002), who suggest that the STC has been spinning down since the 1970s, reducing the amount of cold water that upwells in the Tropics and hence increasing equatorial SST.

\section{c. Present research}

In this paper, we investigate the causes of PDV and EDV in an updated version of the KMK intermediate coupled model. Our purpose is to explore further the processes that might be involved in generating PDV, and in communicating that variability into the Tropics to cause EDV. The coupled model is described in detail in section 2. Its ocean component is a version of the 31/2-layer, reduced-gravity model developed by Lu et al. (1998) that allows layer temperatures to vary. Its atmospheric component consists of an empirical model based on the SVD statistical technique that generates wind stress anomalies from SST anomalies, a simple model of the planetary boundary layer that provides the heat flux forcing for the ocean, and externally prescribed forcing by stochastic wind stress.

Essential parts of the empirical model are structure functions that specify regions $1\left(\theta_{k} \neq 0\right)$ and $2\left(\theta_{k}=\right.$ $0)$ where ocean-to-atmosphere coupling is active and absent, respectively. The functions are specified to eliminate atmospheric teleconnections from the extratropics to the Tropics, so that the only means for such communication is through the oceanic North Pacific STC [section $2 \mathrm{c}(1) \mathrm{v}$ ]. They are varied in a series of test runs in order to identify key regions of ocean-to-atmosphere coupling in the North Pacific [section $4 \mathrm{a}(4)$ ]. They also allow atmospheric teleconnections to be defined in the model, namely, as an atmospheric response in region 2 generated by coupling in region 1 .

As we shall see, for sufficiently large coupling coefficients the model can separately develop two selfsustaining modes of oscillation: a tropical interannual 


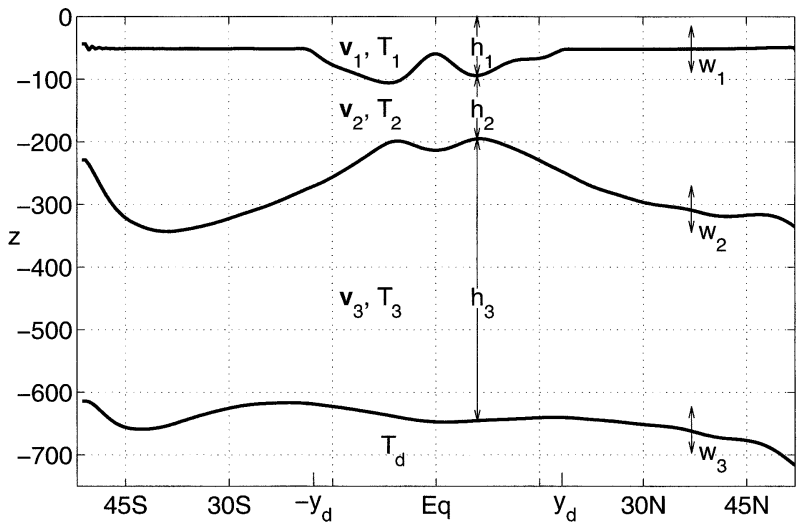

FIG. 1. A section along $140^{\circ} \mathrm{W}$ from the background solution, illustrating the structure of the ocean model.

mode (section 3) and a midlatitude decadal one (section 4). We discuss in detail the feedbacks that maintain the latter oscillation, demonstrate that it can generate EDV by changes in the STC transport (section 4a) and describe solutions with stochastic forcing (section 4c). Finally, we discuss solutions in which both oscillations simultaneously exist (section 5); interestingly, there is a parameter range in which an otherwise damped decadal oscillation is sustained by atmospheric teleconnections from the Tropics.

\section{The coupled model}

\section{a. Model ocean}

Most of the equations of motion for the ocean model are provided in Lu et al. (1998), and so only model details relevant to this study are discussed here. Relevant aspects of the model's STC dynamics are also reviewed.

Figure 1 schematically illustrates the structure of the coupled ocean-atmosphere model. The ocean model consists of three active layers with thicknesses $h_{i}$, velocities $\mathbf{v}_{i}$ and temperatures $T_{i}(i=1,2,3$ is a layer index), overlying a deep, inert layer of temperature $T_{4}$ $=3^{\circ} \mathrm{C}$ where the pressure gradient field is assumed to vanish. Each of the layers corresponds primarily to a single water mass type, namely, surface water, thermocline water, and upper-intermediate water in layers 1,2 , and 3 , respectively. The across-interface velocities, $w_{1}$ and $w_{2}$, allow water to transfer between layers, and they represent all the model's vertical mixing processes (Lu et al. 1998). Heat and momentum are conserved during such transfers.

Temperatures $T_{i}$ are allowed to vary within each layer. They are determined by integrating the equation,

$$
\begin{aligned}
T_{i t}= & -\mathbf{v}_{i} \cdot \nabla T_{i}+\delta_{i 1} \frac{Q_{o}}{\rho_{o} c_{p o} h_{1}}+\frac{Q_{c}}{\rho_{o} c_{p o} h_{1}} \\
& +\left(\kappa_{2} \nabla^{2} T_{i}-\kappa_{4} \nabla^{4} T_{i}\right) \\
& +\frac{1}{h_{1}}\left[w_{i}^{+}\left(T_{i+1}-T_{i}\right)+w_{i-1}\left(T_{i-1}-T_{i}\right)\right],
\end{aligned}
$$

where $\rho_{o}=10^{3} \mathrm{~kg} \mathrm{~m}^{-3}, c_{p o}=4187 \mathrm{~J} \mathrm{~kg}^{-1} \mathrm{~K}^{-1}, \delta_{i 1}$ is the Kronecker $\delta$-symbol, $w_{i}^{+}=\max \left(w_{i}, 0\right), w_{i}^{-}=$ $\min \left(w_{i}, 0\right)$, and $w_{0}=w_{4}=0$. From left to right, the terms represent the rate of change of temperature $T_{i t}$ due to horizontal advection, surface heat flux into the ocean $Q_{o}$, heat flux due to convective overturning $Q_{c}$, Laplacian and biharmonic mixing with coefficients $\kappa_{2}=2$ $\times 10^{7} \mathrm{~cm}^{2} \mathrm{~s}^{-1}$ and $\kappa_{4}=2 \times 10^{21} \mathrm{~cm}^{4} \mathrm{~s}^{-1}$, and vertical mixing from above and below. The formulation of the last two terms ensures that vertical mixing conserves heat, $Q_{o}$ is specified below in Eqs. (4), (12), (19), and $Q_{c}$ is determined as in McCreary and Lu (1994).

For our purposes, $w_{1}$ is the important mixing velocity since it determines the locations of the ascending and descending branches of the model STCs. The primary processes that contribute to $w_{1}$ are upwelling $w_{e}$ and subduction $w_{s}$. According to the Kraus-Turner (1967) model, wind stirring entrains (upwells) water into the mixed layer whenever it becomes sufficiently thin. We parameterize this process by

$$
w_{e}=\frac{\left(h_{1}-H_{e}\right)^{2}}{H_{e} t_{e}} S\left(H_{e}-h_{1}\right),
$$

where $H_{e}=50 \mathrm{~m}, t_{e}=1$ day, and $S$ is a step function (McCreary and Kundu 1988). We parameterize detrainment (subduction) by

$$
w_{s}=\frac{\left(h_{1}-H_{s}\right)^{2}}{H_{s} t_{s}} S\left(h_{1}-H_{s}\right) S\left(|y|-y_{d}\right),
$$

where $H_{s}=H_{e}$ and $t_{s}=t_{e}$. Subduction is confined primarily to the subtropics where there is a strong meridional SST gradient, and to represent this property we suppress detrainment equatorward of latitudes $\pm y_{d}$, where $y_{d}=18^{\circ}$ (McCreary and Lu 1994). Thus, these "subduction cutoff latitudes" define the boundaries between the subtropics and Tropics in our model. According to (2a) and (2b), $h_{1}$ necessarily remains close to $H_{e}$ poleward of $\pm y_{d}$, and so simulates a mixed layer of nearly constant thickness.

In solutions forced by steady winds, a measure of the strength of the northern (southern) STC is the zonally integrated surface-layer meridional transport,

$$
\begin{aligned}
M_{1}\left(y^{\prime}\right) & =\int_{x_{w}}^{x_{e}} h_{1} \frac{p_{1 x}}{f} d x+\int_{x_{w}}^{x_{e}} \frac{\tau^{x}}{f} d x \\
& \equiv G\left(y^{\prime}\right)+E\left(y^{\prime}\right),
\end{aligned}
$$

where $y^{\prime}= \pm y_{d}$, and $x_{w}\left(y^{\prime}\right)$ and $x_{e}\left(y^{\prime}\right)$ are the longitudes of the western and eastern boundaries of the basin (McCreary and Lu 1994; Lu et al. 1998). These transports drain warm surface (layer-1) water from the Tropics, and the resulting mass loss is necessarily balanced by an upwelling transport of cool thermocline (layer-2) water near the equator $\mathcal{W}$, and the convergence of layer2 water $M_{2}\left(y^{\prime}\right)$.

McCreary and Lu (1994) showed that much of $M_{1}\left(y^{\prime}\right)$ is determined by the Ekman transport $E\left(y^{\prime}\right)$. Thus, the 
model contains an explicit process by which subtropical zonal winds, $\tau^{x}\left(x, y^{\prime}\right)$, affect the amount of thermocline water that upwells along the equator. Note that STC strength is not determined by midlatitude wind stress curl, as might be expected. It is true that an increase in midlatitude wind curl does increase subduction by a proportionate amount, but the additional subducted water can recirculate within the subtropical gyres and need not flow into the tropical ocean. It will do so only if the wind curl anomaly also acts to increase the Ekman divergence out of the Tropics, according to (3).

When the winds are not steady, the simple notion of a closed STC in which $M_{1}\left(y^{\prime}\right)=\mathcal{W}=M_{2}\left(y^{\prime}\right)$ breaks down. Klinger et al. (2002) recently explored time variability of the STC by forcing the KMK ocean model with various switched-on and oscillatory, idealized wind stress fields. They found that $M_{2}\left(y_{d}\right)$ lagged $M_{1}\left(y_{d}\right)$ by up to $5 \mathrm{yr}$, a consequence of the slow geostrophic adjustment of the thermocline by wave propagation. As we shall see, however, the steady-state concepts still help in the interpretation of our decadal solutions (section $4 b)$.

\section{b. Background state}

To determine the background state for the coupled solutions, the ocean model is first spun up to equilibrium using annual-mean Hellerman and Rosenstein (1983) wind stress, $\tau^{*}$, multiplied by a factor of 0.7 since these winds are believed to be too strong in the Tropics (Harrison 1989), and a surface heat flux $Q_{o}$ given by

$$
Q_{r}=\frac{\rho_{o} c_{p o} H_{1}}{t_{h}}\left(T^{*}-T_{1}\right),
$$

where $H_{1}=100 \mathrm{~m}, t_{h}=30$ days, and $T^{*}$ is the annualmean SST field from Reynolds and Smith (1994). This solution is spun up for $100 \mathrm{yr}$ or more, by which time it has adjusted close to equilibrium. The resulting SST field, $\bar{T}_{1}$, provides the background SST field for the atmospheric model. The background wind and heat flux fields are $\tau^{*}$ and $Q_{r}\left(\bar{T}_{1}\right)$.

Other background fields needed by the model atmosphere are wind speed $W^{*}$ and air temperature $\bar{T}_{a}$. The $W^{*}$ field is the annual-mean wind speed field from the Comprehensive Ocean-Atmosphere Dataset (COADS). The $\bar{T}_{a}$ field is determined by solving (14) with $T_{1}$ in the equation for $Q_{s},(13 \mathrm{~b})$, replaced by $\bar{T}_{1}$.

\section{c. Model atmosphere}

The model atmosphere consists of two basic parts: an empirical model that produces wind stress anomalies $\Delta \boldsymbol{\tau}$ from model SST anomalies $\Delta T_{1}=T_{1}-\bar{T}_{1}$, and a boundary layer model that generates heat flux anomalies $\Delta Q$ and $\Delta T_{1}, \Delta \tau$, and air temperature anomalies $\Delta T_{a}$. A third part specifies stochastic wind stress forcing from observed wind stress variability.

\section{1) EMPIRICAL MODEL}

The empirical model is constructed from simultaneous relationships between observed wind stress and SST anomalies determined by the singular value decomposition (SVD) statistical technique. The advantage of this approach is that it builds observed patterns of ocean-atmosphere variability directly into the system. Its limitation is that cause and effect are confused, since the model explicitly assumes that wind stress patterns are always generated as a response to SST anomalies. To address this limitation, we include structure functions $\theta_{k}$, defined later in Eqs. (8) and (11), to suppress oceanto-atmosphere interaction in specific regions. Section $2 c(1)$ ii provides a general discussion of the issue, focusing on our use of simultaneous, rather than lagged, SVDs.

\section{(i) SVDs}

The datasets used to calculate the SVDs are monthly Global Sea Ice and Sea Surface Temperature (GISST) data for SST (Parker et al. 1994) and monthly COADS data for wind stress (as analyzed and corrected for biases by da Silva et al. $1994 \mathrm{a}, \mathrm{b})$ for the $40-\mathrm{yr}$ period from 1949 to 1989 . The data are interpolated from a $1^{\circ} \times 1^{\circ}$ grid onto a $5^{\circ} \times 4^{\circ}$ grid, and the domain is the Pacific basin from $55^{\circ} \mathrm{S}$ to $55^{\circ} \mathrm{N}$.

The SVDs are calculated following Bretherton et al. (1992). Let $\mathbf{S}(t)$ be the observed SST anomalies and $\mathbf{W}(t)$ be the observed zonal and meridional wind stress anomalies, both written as column vectors at $\mathcal{N}$ spatial grid points. The covariance matrix between these two fields is defined as

$$
\mathbf{C}=\left\langle\mathbf{S}(t) \mathbf{W}^{\mathrm{T}}(t)\right\rangle,
$$

where the operator $\langle q\rangle$ denotes the time average of $q(t)$, and the transpose operation is denoted by a superscript T. Note that, since $\mathbf{W}$ has dimension $2 \mathcal{N}$, the dimension of $\mathbf{C}$ is $\mathcal{N} \times 2 \mathcal{N}$.

The SVD technique represents $\mathbf{C}$ in the form

$$
\mathbf{C}=\sum_{k=1}^{\mathcal{N}} \sigma_{k} \mathbf{l}_{k} \mathbf{r}_{k}^{\mathrm{T}},
$$

where $\mathbf{l}_{k}$ and $\mathbf{r}_{k}$ are eigenfunctions of $\left(\mathbf{C} \mathbf{C}^{\mathrm{T}}\right) \mathbf{l}_{k}=\sigma_{k}^{2} \mathbf{l}_{k}$ and $\left(\mathbf{C}^{\mathrm{T}} \mathbf{C}\right) \mathbf{r}_{k}=\sigma_{k}^{2} \mathbf{r}_{k}$, normalized so that $\mathbf{l}_{j}^{\mathrm{T}} \mathbf{l}_{k}=\mathbf{r}_{j}^{\mathrm{T}} \mathbf{r}_{k}=$ $\delta_{j k}$. The eigenvalues $\sigma_{k}^{2}$ are the total squared covariance explained by each eigenfunction pair, and, for convenience, they are ordered from the largest $\left(\sigma_{1}^{2}\right)$ to smallest $\left(\sigma_{\mathscr{C}}^{2}\right)$ value. We refer to $\mathbf{l}_{k}$ and $\mathbf{r}_{k}$ as patterns for observed SST and wind stress anomalies, respectively, associated with the $k$ th eigenvectors (SVD $k$ ). In addition, $\mathbf{r}_{k}$ can be divided into two parts (in the same order that $\mathbf{W}$ was constructed), yielding patterns for zonal and meridional wind stress anomalies, $\mathbf{r}_{k}^{x}$ and $\mathbf{r}_{k}^{y}$.

Figure 2 displays the first four SVDs determined from monthly mean data, which contain $51 \%, 9 \%, 5 \%$, and $4 \%$ of the squared covariance, respectively. SVD1 cap- 

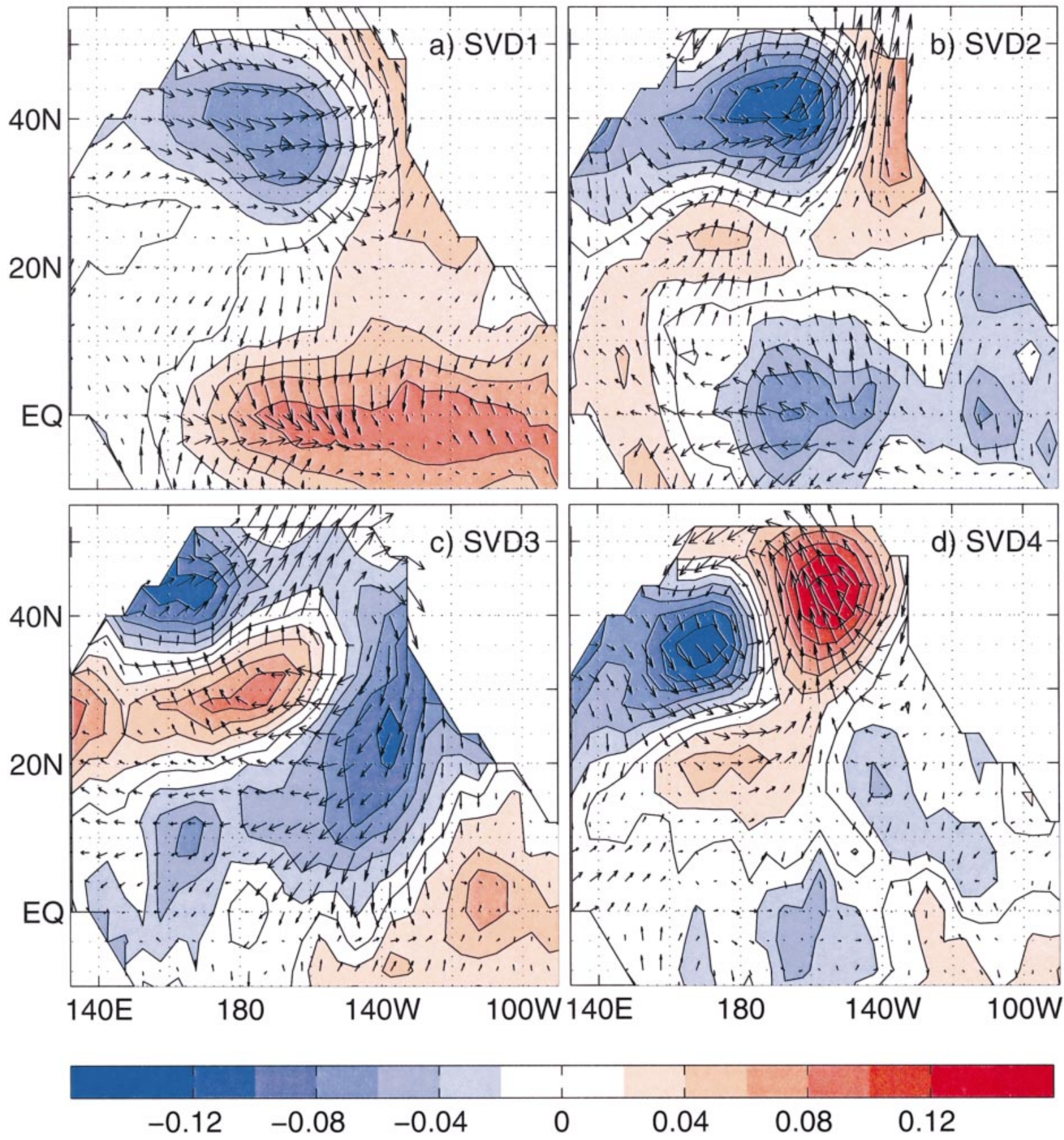

FIG. 2. Spatial patterns of the first four SVDs, showing $\Delta T_{1}$ (contours) and $\Delta \boldsymbol{\tau}$ (arrows) patterns. Both fields are nondimensional.

tures the ENSO interannual variation, having a large amplitude in the equatorial region and a teleconnection pattern to midlatitudes (Alexander 1992; Deser and Blackmon 1995; Lau and Nath 1996). SVD2 has a broad SST minimum in the central North Pacific, with southeasterly wind stress in the eastern ocean; it is very similar to the preferred spatial pattern of internal atmospheric variability found in observations [section $2 c(3)$ ] and in stand-alone atmospheric GCMs forced by fixed
SSTs (see, e.g., Fig. 15 in Neelin and Weng 1999), and closely resembles one of the SVDs determined from wind stress and SST tendency [section 2c(1)ii]. SVD3 consists of an anticyclone in the eastern North Pacific, with a prominent zonal-wind component in the subtropics $\left(10^{\circ}-30^{\circ} \mathrm{N}\right)$ across much of the basin; SST/wind stress patterns similar to SVD3 developed in the coupled GCM of Latif and Barnett (1994, 1996), and the wind pattern resembles the response of an atmospheric GCM 
coupled with a slab ocean model to an imposed SST perturbation in the Kuroshio Extension region (Yulaeva et al. 2001). Prominent features of SVD4 are similar to the negative of those in SVD3, but they are shifted poleward by about $10^{\circ}$ and westward by about $30^{\circ}$. Modes 5-7 predominantly have a midlatitude, largescale character, and the higher-order modes exhibit small-scale (noisy) structures.

\section{(ii) Discussion}

A number of studies have demonstrated that simultaneous cross correlations between SST and atmospheric variables can result from prior forcing by atmospheric noise (e.g., Frankignoul 1985; correspondence between Frankignoul, 1999, and Barnett and Latif, 1999, 2000). If our SVDs are determined solely by this mechanism, then their patterns result entirely from atmosphere-toocean processes and there is a fundamental inconsistency with the formulation of our empirical model. Here, we report on additional sets of SVDs that we obtained to investigate this issue, and to explore how to minimize the influence of atmospheric noise in our model.

We obtained sets of SVDs using data that were temporally averaged by $J$-month running-mean filters (with $J=3,5$, and 7) and seasonally stratified, centered on either January or July. For each $J$, the first four wintertime SVDs are all very similar to the monthly mean SVDs shown in Fig. 2, whereas the summertime SVDs are not. (Differences between corresponding patterns in the monthly mean and wintertime SVDs are largely attributable to the influence of summertime variability in the monthly mean SVDs.) Thus, the monthly mean SVDs capture patterns of wintertime variability that can persist for up to 7 months and vary interannually. Averages of 7 months would be expected to enhance correlations due to ocean-to-atmosphere feedbacks relative to atmosphere-to-ocean feedbacks, which decorrelate on timescales less than 10 days.

We also obtained lagged auto- and cross correlations of the SST and wind stress time series for each SVD [ $s_{k}$ and $w_{k}$ defined in (9) below]. Cross correlations for all the wintertime SVDs except SVD3 and SVD4 fall off rapidly, becoming zero at lags close to \pm 1 yr. In contrast, the cross correlations for wintertime SVD3 and SVD4 become zero at lags of about $\pm 2 \mathrm{yr}$, remain negative until $\pm 10 \mathrm{yr}$, and attain relative minima between about \pm 6 and \pm 8 yr. Thus, the wintertime SVDs 3 and 4 are associated with decadal variability with a period of 12-16 yr. The cross correlations for SVD3 at a lag of $-8 \mathrm{yr}$ exceeds the $99 \%$ significance level based on a Student's $t$ test. The decadal signal is also seen in the cross correlations for monthly mean SVD3 when only wintertime data is considered.

To help identify prominent patterns of atmosphereto-ocean forcing during winter, we obtained sets of SVDs (labelled SVD $k^{\prime}$ ) between wind stress $\overline{\mathbf{W}}(t)$ and SST tendency, $\Delta \overline{\mathbf{S}}(t) \equiv \overline{\mathbf{S}}(t+n)-\overline{\mathbf{S}}(t-n)$, where $t$ is January and the overbar designates smoothing by a 3-month running-mean filter. Atmosphere-to-ocean forcing is expected to be predominant in regions where $\mathrm{SVD} k$ closely resembles SVD $k^{\prime}$; conversely, ocean-toatmosphere feedback may be active in regions where they differ (Wallace et al. 1990; Deser and Timlin 1997). The resulting SVDs are almost unchanged for $n=1$, 2, and 3 months. SVD1' is similar to SVD1 in Fig. 2 north of $20^{\circ} \mathrm{N}$ but the sign of the SST anomaly is reversed in the equatorial band, consistent with the existence of ocean-to-atmosphere forcing in the Tropics and atmospheric teleconnections to midlatitudes. SVD2' resembles SVD2 in Fig. 2 north of $10^{\circ} \mathrm{N}$ and is weak elsewhere, and it is even more similar to SVD2 determined from $J=3$ wintertime data. SVD2' is also similar to the dominant North Pacific SST-tendency modes reported by Wallace et al. (1990) and Deser and Timlin (1997). We conclude that SVD2 is largely determined by atmosphere-to-ocean forcing, and for this reason do not include it in the model atmosphere [section $2 \mathrm{c}(1) \mathrm{v}$ ]. SVD3' does not resemble SVD3 at all, particularly in the northwest Pacific where SVD3' is weak and SVD3 is strong. SVD4' is concentrated in the eastern and central North Pacific, with little amplitude in the northwest ocean. That SVD3 does not resemble either SVD3' or SVD4' thus allows for the possibility that it is influenced by ocean-to-atmosphere coupling, particularly in the northwest region.

Finally, we explored the use of lagged SVDs, in which SST leads the atmospheric variables by $n$ months, as a means for removing the effects of atmospheric noise from the model atmosphere. Although the method is physically appealing, it is problematic from the view point of time series analysis, since the use of $n$-month lagged data alone is not a good filter of $n$-month noise. Despite this reservation, we constructed a version of the coupled model using SVDs determined when winds lagged SST by $n=1$ month (lag-1 SVDs). SVD1 was not much changed from its lag-0 counterpart, but SVD3 and SVD4 were. As a result, the coupled solution was able to generate a self-sustaining decadal oscillation only when the amplitude factor $\phi_{o}$ (defined below) was increased to 4.0. The weakening of the decadal mode in this solution could have resulted from elimination of spurious atmosphere-to-ocean feedbacks in the system. It may also have occurred because high-frequency noise was aliased into the structures of SVD3 and SVD4, a conclusion supported by the similarity between the lag0 , monthly mean, and wintertime SVDs noted earlier.

\section{(iii) Specification of $\Delta \boldsymbol{\tau}$}

We assume that model wind stress and SST anomalies are related just as in the observed SVDs. Let $\Delta \tau^{a}\left(x_{i}, y_{j}, t\right)$ represent the model wind stress anomaly at time $t$ and observational data point $\left(x_{i}, y_{j}\right)$, where superscript $a$ is either $x$ or $y$ to denote the zonal or meridional wind component. There are $N_{x}$ grid points 
in the zonal direction, $N_{y}$ grid points in the meridional direction, and $\mathcal{N}=N_{x} N_{y}$. We then synthesize $\Delta \tau^{a}\left(x_{i}\right.$, $\left.y_{j}, t\right)$ from the series of observed wind stress SVDs, $r_{k}^{a}\left(x_{i}, y_{j}\right)$, according to

$$
\Delta \tau^{a}\left(x_{i}, y_{j}, t\right)=\sum_{k=1}^{N} a_{k}(t) \phi_{k}\left(x_{i}, y_{j}\right) c_{k} r_{k}^{a}\left(x_{i}, y_{j}\right),
$$

where

$$
a_{k}(t)=\frac{\sum_{i=1}^{N_{x}} \sum_{j=1}^{N_{y}} \theta_{k}\left(x_{i}, y_{j}\right) \Delta T_{1}\left(x_{i}, y_{j}, t\right) l_{k}\left(x_{i}, y_{j}\right)}{\sum_{i=1}^{N_{x}} \sum_{j=1}^{N_{y}} \theta_{k}\left(x_{i}, y_{j}\right) l_{k}^{2}\left(x_{i}, y_{j}\right)}
$$

is the projection of the model SST anomaly $\Delta T_{1}\left(x_{i}, y_{j}, t\right)$ onto $l_{k}\left(x_{i}, y_{j}\right)$ modified by the structure function $\theta_{k}, N$ is the number of SVDs retained in the model, and $c_{k}$ is the coupling coefficient that links the temperature and wind stress patterns associated with SVD $k$ [section 2c(1)iv]. To be used by the ocean model, $\Delta \tau^{a}$ must be interpolated onto the model grid at each time step of the integration; likewise, to evaluate (8) $\Delta T_{1}$ must be interpolated onto the observational grid.

The structure functions, $\theta_{k}\left(x_{i}, y_{j}\right)$ and $\phi_{k}\left(x_{i}, y_{j}\right)$, are specified to limit the area over which ocean-to-atmosphere and atmosphere-to-ocean coupling occurs, respectively [section $2 \mathrm{c}(1) \mathrm{v}$ ]. In so doing, $\theta_{k}$ can artificially weaken $a_{k}(t)$, and the factor in the denominator of (8) is included to compensate for this tendency.

\section{(iv) Coupling coefficients}

Time series of expansion coefficients for the temperature and wind stress patterns associated with SVDk are

$$
s_{k}(t)=\mathbf{l}_{k}^{\mathrm{T}} \cdot \mathbf{S}, \quad w_{k}(t)=\mathbf{r}_{k}^{\mathrm{T}} \cdot \mathbf{W},
$$

respectively. The two time series are similar, but not identical, the cross correlation between them being $\left\langle s_{k} w_{k}\right\rangle /\left(\left\langle w_{k}^{2}\right\rangle^{1 / 2}\left\langle s_{k}^{2}\right\rangle^{1 / 2}\right)$. If we seek a best-fit relationship of the form $w_{k}^{\prime}=c_{k} s_{k}$, then a least squares analysis yields

$$
c_{k}=\frac{\left\langle s_{k} w_{k}\right\rangle}{\left\langle s_{k}^{2}\right\rangle}
$$

for the coupling coefficient between $w_{k}$ and $s_{k}$. It is worth noting that other choices for $c_{k}$ have been used in previous studies; for example, Neelin and Weng (1999) and KMK set $c_{k}=\left\langle w_{k}^{2}\right\rangle^{1 / 2} /\left\langle s_{k}^{2}\right\rangle^{1 / 2}$, which yields significantly larger coefficient values than (10) does.

\section{(v) Specification of $N, \theta_{k}$, and $\phi_{k}$}

We carried out a large number of test runs to determine appropriate structure functions and a value for $N$. To simplify the model dynamics, we seek to use as few SVDs as possible. Solutions with $N=3$ were not able to develop a decadal oscillation. Solutions for $N \geq 4$ are all very similar to each other, their interannual and decadal oscillations virtually unchanged. Furthermore, this property also holds when SVD2, which is likely to be determined mostly by atmosphere-to-ocean forcing [section 2c(1)ii]. is dropped from the model atmosphere.

Based on these tests, as well as our analyses of SSTtendency SVDs [section 2c(1)i], unless specified otherwise we take $N=4$ and choose $\theta_{k}$ and $\phi_{k}$ for $k=1$ and 2 to be

$$
\begin{aligned}
& \theta_{1}=S\left(12^{\circ}-|y|\right), \quad \phi_{1}=1.3, \\
& \theta_{2}=\phi_{2}=0,
\end{aligned}
$$

and for $k>2$ to be

$$
\theta_{k}=S\left(y-12^{\circ}\right), \quad \phi_{k}=\phi_{o} S\left(y-12^{\circ}\right),
$$

where $\phi_{o}=1.3$. With these choices for $\theta_{k}$, the denominator of (8) has the values $0.61,0.64$, and 0.66 for $k$ $=1,3$, and 4 , respectively. Solutions for other choices of $\theta_{3}$ and $\theta_{4}$, which subdivide the North Pacific into separate quadrants, are discussed in section $4 \mathrm{a}(4)$.

As noted above, SVD1 clearly represents variability associated with ENSO. It is generally accepted that ENSO is driven by ocean-to-atmosphere interactions confined near the equator, which in turn cause atmospheric teleconnections from the Tropics to the extratropics (e.g., Lau and Nath 1996). The choices for $\theta_{1}$ and $\phi_{1}$ in (11a) build in both of these properties. The choices for $\theta_{k}$ and $\phi_{k}$ in (11c) specify that all ocean-toatmosphere coupling is confined poleward of $12^{\circ} \mathrm{N}$, and that there are no atmospheric teleconnections back to the near-equatorial band. The differences between (11a) and (11c) allow a clean separation in the model atmosphere between near-equatorial and extratropical coupling, and as we shall see the two parts generate interannual and decadal oscillations, respectively.

Setting $\phi_{o}=\phi_{1}=1.3$ effectively strengthens coupling in the model by $30 \%$. We chose this value for our main run because it is slightly above the minimum value that allows the system to develop self-sustaining interannual and decadal oscillations. A possible reason that an increase is required for $\phi_{1}$ is that the tropical coupling associated with ENSO is not entirely contained in SVD1, some of it being spread into SVD2 and SVD3 (Fig. 2). A similar spreading may account for the need to increase $\phi_{o}$. On the other hand, both modes of oscillation may be damped (Thompson and Battisti 2000; Barnett et al. 1999; Schneider et al. 2002), and so we report solutions for smaller values of $\phi_{o}$ and $\phi_{1}$ as well.

\section{2) ATMOSPHERIC BOUNDARY LAYER MODEL}

The atmospheric boundary layer model determines the anomalous heat flux $\Delta Q$ into the ocean as a function of $T_{1}$, boundary layer air temperature $T_{a}$, and wind speed $W$. It is given by

$$
\Delta Q=Q\left(T_{1}, T_{a}, W\right)-Q\left(\bar{T}_{1}, \bar{T}_{a}, W^{*}\right),
$$

where 


$$
Q=Q_{s}+Q_{l}+Q_{\mathrm{lw}},
$$

$Q_{\mathrm{lw}}$ is outgoing longwave radiation, which is a function of $T_{1}$ and surface humidity as parameterized in Kleeman and Power (1995),

$$
Q_{s}=W \rho_{a} c_{p} C_{s}\left(T_{a}-T_{1}\right)
$$

is the sensible heat flux, and

$$
Q_{l}=W \rho_{a} c_{p} C_{E}\left[q_{a}-q_{s}\left(T_{1}\right)\right]
$$

is the latent heat flux. Note that $Q$ does not involve shortwave radiation fluxes, $Q_{\text {sw }}$, so that the model neglects feedback of $T_{1}$ onto cloud cover. In $Q_{s}$ and $Q_{l}$, $C_{s}$ and $C_{E}$ are drag coefficients (evaluated following Large and Pond 1981, 1982), $\rho_{a}$ is the density if surface air set equal to $1.3 \mathrm{~kg} \mathrm{~m}^{-3}$, and $c_{p}=1004.64 \mathrm{~J} \mathrm{~kg}^{-1}$ $\mathrm{K}^{-1}$ is the specific heat of the atmosphere. The specific humidity of the air is taken to be $q_{a}=r q_{s}\left(T_{a}\right)$, where $r$ is the relative humidity set equal to 0.8 , and $q_{s}$ is the saturation specific humidity.

Air temperature $T_{a}$ is determined by integrating the equation

$$
T_{\text {at }}=\frac{Q_{s}}{\rho_{a} c_{p} H}+\kappa_{a} \nabla^{2} T_{a},
$$

where $\kappa_{a}=3 \times 10^{6} \mathrm{~m}^{2} \mathrm{~s}^{-1}$ following Kleeman and Power (1995), and $H=1 \mathrm{~km}$ is the thickness of the planetary boundary layer (assumed constant). Including diffusion in the model allows a physically realistic scaledependent heat flux response to SST anomalies (see Kleeman and Power, 1995, for further discussion of this point). Including sensible heat fluxes allows for the rapid adjustment of boundary layer air temperature to changes in SST. Test runs with a more sophisticated atmospheric boundary layer model indicated that these were the dominant processes that needed to be considered in our anomaly coupled model. The equation is solved over the model domain. Over land the lower boundary temperature is fixed to climatology.

The wind speed that is used to calculate $Q_{s}$ and $Q_{l}$ is

$$
W=W^{*}+\Delta W
$$

where the wind speed anomaly $\Delta W$ is determined from $\Delta \tau$ according to

$$
\Delta W=\frac{1}{\rho_{a} C_{d}}\left(|\boldsymbol{\tau}|^{1 / 2}-\left|\boldsymbol{\tau}^{*}\right|^{1 / 2}\right),
$$

$\boldsymbol{\tau}=\boldsymbol{\tau}^{*}+\Delta \boldsymbol{\tau}, C_{d}=1.4 \times 10^{-3}$, and $\rho_{a}=1.3 \mathrm{~kg} \mathrm{~m}^{-3}$.

\section{3) Stochastic FORCING}

For some of the solutions reported in sections $4 \mathrm{c}$ and 5 , a stochastic wind stress anomaly $\Delta \boldsymbol{\tau}^{\prime}$ in the North Pacific is included as a part of the wind stress anomaly $\Delta \boldsymbol{\tau}$ that forces the model. It is determined from $\mathbf{W}$ according to

$$
\Delta \boldsymbol{\tau}^{\prime}=\sum_{i=1}^{40} b_{i}\left\langle w_{i}^{2}\right\rangle^{1 / 2} \mathbf{e}_{i},
$$

where $\mathbf{e}_{i}$ is an EOF of $\mathbf{W}$ in the region north of $12^{\circ} \mathrm{N}$, $w_{i}(t)$ is the principal component of $\mathbf{e}_{i}$, and $b_{i}(t)$ is a time series of random numbers with $\left\langle b_{i}^{2}\right\rangle^{1 / 2}=1$ that is varied every 30 days. The first 40 EOFs explain $99 \%$ of the variance of $\mathbf{W}$, and EOF1 closely resembles the wind stress pattern of SVD2 (Fig. 2). Thus, $\Delta \boldsymbol{\tau}^{\prime}$ is a representation of observed atmospheric variability north of $12^{\circ} \mathrm{N}$ on timescales of 30 days and longer.

\section{d. Coupling}

In the coupled model, the ocean model passes $T_{1}$ to the atmospheric model, and the atmospheric model returns $\boldsymbol{\tau}$ and $Q_{o}$. The total wind stress field that drives the ocean model is

$$
\boldsymbol{\tau}=\boldsymbol{\tau}^{*}+\Delta \boldsymbol{\tau}
$$

and the total heat flux is

$$
Q_{o}=Q_{r}\left(\bar{T}_{1}\right)+\Delta Q .
$$

Note that when $T_{1}=\bar{T}_{1}$, and there is no externally imposed stochastic forcing $\Delta \boldsymbol{\tau}^{\prime}, \boldsymbol{\tau}$ and $Q_{o}$ reduce to the forcing fields for the background state as they should.

\section{e. Numerics}

The model basin is an idealized representation of the Pacific basin from $55^{\circ} \mathrm{S}$ to $55^{\circ} \mathrm{N}$. The ocean model uses a standard Arakawa C-grid with a resolution of $\Delta x=$ $1^{\circ}, \Delta y=0.5^{\circ}$, and the equations of motion are integrated forward in time with a time step of $\Delta t=72 \mathrm{~min}$. The time step used for Eq. (14) is $24 \mathrm{~min}$, so that it is called 3 times for each ocean model time step. Initial layer thicknesses are $H_{1}=50 \mathrm{~m}, H_{2}=150 \mathrm{~m}$, and $H_{3}=$ $450 \mathrm{~m}$. As the integration proceeds, layer thicknesses vary but total mass (summed over all layers) does not.

Both the background integrations and the anomaly coupled integrations are run for at least 100 model years. The model is computationally very efficient, which made it possible to carry out many (literally hundreds) test runs.

\section{Interannual solutions}

To investigate the basic dynamics of the model's interannual mode, we isolate it by retaining only SVD1 in the model atmosphere, that is, by setting $N=1$ in (7). For the model parameters listed in section $2 \mathrm{c}$, the system then develops only an interannual oscillation with a period of $4.3 \mathrm{yr}$, and, according to (11a), it exists independent of extratropical $\left(|y|>12^{\circ} \mathrm{N}\right)$ feedbacks.

Figure 3 shows $\Delta T_{1}$ and $\Delta \boldsymbol{\tau}$ at the peak of the warm phase of the interannual oscillation. (Since $N=1, \Delta \boldsymbol{\tau}$ is just a replot of the wind vectors in SVD1 in Fig. 2a.) The pattern is dominated by SST anomalies in the Niño$3.5\left(5^{\circ} \mathrm{S}-5^{\circ} \mathrm{N}, 180^{\circ}-120^{\circ} \mathrm{W}\right)$ region, consistent with the peak of an ENSO event. Unlike observed ENSO, however, SST anomalies in the eastern equatorial ocean have 


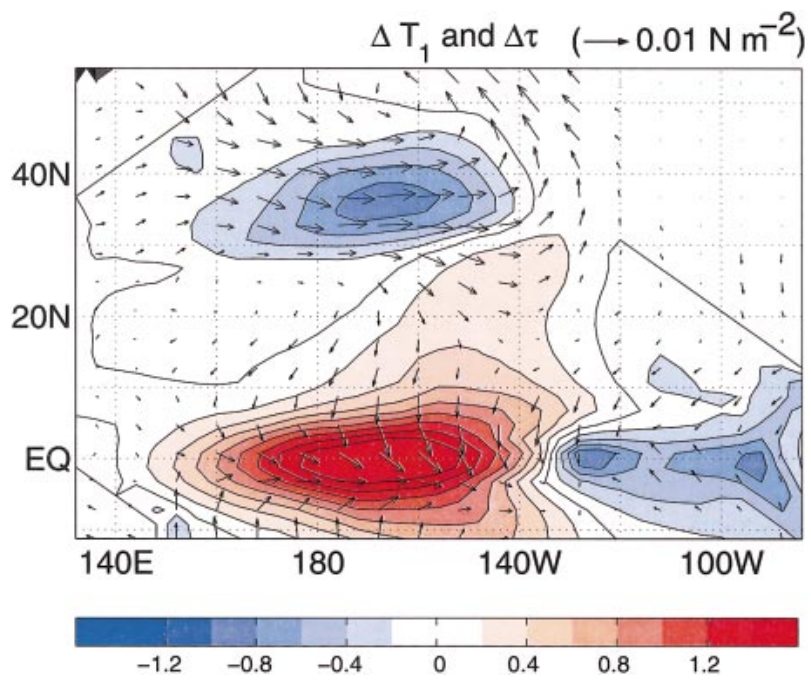

FIG. 3. Structure of the interannual solution at the peak of its warm phase, showing $\Delta T_{1}$ (contours) and $\Delta \boldsymbol{\tau}$ (arrows) anomalies. Units for $\Delta T_{1}$ are $1^{\circ} \mathrm{C}$ an opposite sign to those in Niño-3.5. This difference is likely due to SVD1 not completely representing ENSO wind variability, as equatorial wind anomalies are associated with the other SVDs as well (Fig. 2). There is also a significant extratropical response, due to atmospheric teleconnections, with about half the observed amplitude.

Model sea level is given by

$$
d=\alpha\left[\left(T_{1}-T_{4}\right) h_{1}+\left(T_{2}-T_{4}\right) h_{2}+\left(T_{3}-T_{4}\right) h_{3}\right],
$$

where $\alpha=0.00025^{\circ} \mathrm{C}^{-1}$ is the temperature expansion coefficient. Figure 4 plots sea level anomalies $(\Delta d=d$ $-\bar{d}$ where $\bar{d}$ is the sea level of the background state) and layer-1 current anomalies $\left(\Delta \mathbf{v}_{1}\right)$ over half of the primary cycle; the other half (corresponding to phases $\theta=180^{\circ}, 225^{\circ}, 270^{\circ}$, and $315^{\circ}$ ) essentially being the negative images of corresponding panels in the figure. The phase $\theta=0^{\circ}$ is chosen to coincide with maximum equatorial $\Delta T_{1}$. Figures $4 \mathrm{a}$ and $4 \mathrm{~b}, \theta=0^{\circ}$ and $45^{\circ}$, respectively, show the expected response to equatorial
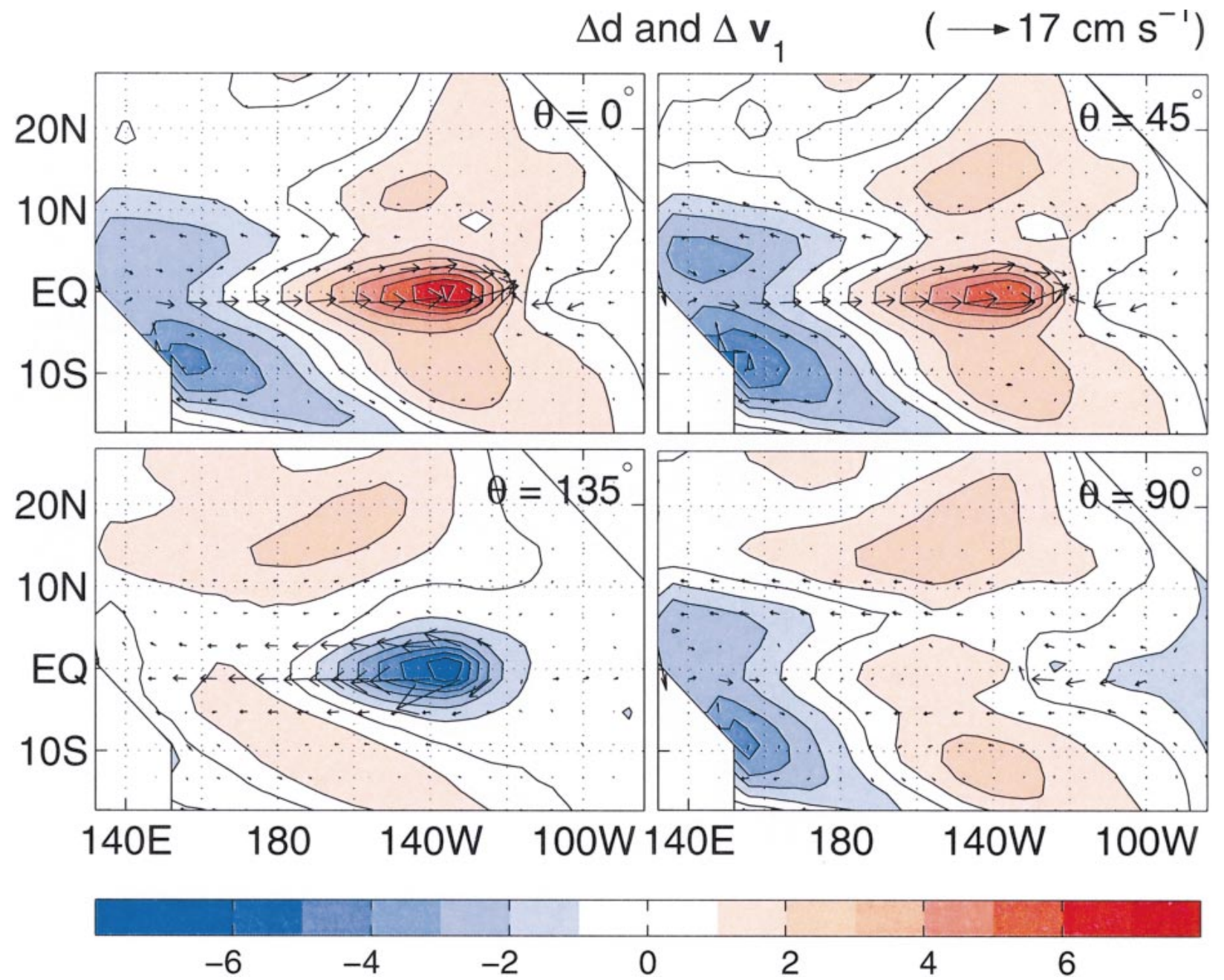

FIG. 4. Phase ( $\theta$ ) evolution of $\Delta d$ (contours) and $\Delta \mathbf{v}_{1}$ (vectors) for the interannual solution. Units for $\Delta d$ are $1 \mathrm{~cm}$. 
westerlies confined in the central Pacific: There is an upward tilt to the east along the equator to balance the wind, regions of shallow $\Delta d$ on either side of the equator driven by Ekman suction, and an eastward equatorial current associated with anomalous downwelling near $135^{\circ} \mathrm{W}$. Figure 4 also exhibit westward propagation of off-equatorial $\Delta d$ : Regions of positive off-equatorial $\Delta d$ that appear near $140^{\circ} \mathrm{W}$ at $\theta=0^{\circ}$ shift westward from $\theta=45^{\circ}$ to $135^{\circ}$, and they reach the western boundary at $\theta=180^{\circ}$ where they are intensified by the nearequatorial winds.

All the expected features of the ENSO time-delayed oscillator are therefore present in the solution. The essential aspect of this paradigm is that the wind stress anomalies that are responsible for the amplification of an ENSO event also lead to its demise (so that regions 1 and 2 are in close proximity): They excite off-equatorial Rossby waves that reflect at the western boundary as equatorial Kelvin waves, which subsequently trigger negative ocean-to-atmosphere feedbacks in the eastern and central oceans. In our solution, evidence for this reflection is the region of $-\Delta d$ in the eastern, equatorial ocean from $\theta=0^{\circ}$ to $\theta=90^{\circ}$, a period of time when wind anomalies predominantly have a westerly component along the equator (the exception being the weak easterlies in the eastern ocean): Because the equatorial ocean is close to equilibrium at a period of $4.3 \mathrm{yr}$, the layer-1 pressure change along the equator (a close proxy to the change in $d)$ is given by $p_{1 e}=p_{1 w}+(1 / g)$ $\int_{x_{w}}^{x_{e}}\left(\tau^{x} / h_{1}\right) d x$, where $p_{1 e}$ and $p_{1 w}$ are the pressures at $x_{e}$ and $x_{w}$, respectively; since the the integral is positive, the only way $p_{1 e}$ can be negative is for $p_{1 w}$ to be even more negative, which can only result from remote forcing. The region of $-\Delta d$ is associated with a westward equatorial current that advects cool water westward, weakening the warm $T_{1}$ anomaly in the Niño-3.5 region and leading to the termination of the model ENSO by weakening the positive projection of $\Delta T_{1}$ onto SVD1.

With $\phi_{1}=1.3$, the interannual signal is thus selfsustaining. When $\phi_{1}$ is increased to 1.4 , the amplitude of the oscillation is increased, but its period and horizontal structure do not change. When $\phi_{1}$ is reduced to 1.2 , however, the oscillation is damped and the solution eventually adjusts to a steady state.

\section{Decadal solutions}

In this section, we isolate the decadal mode by deleting SVD1 from the model atmosphere, by starting the sum in (7) at $k=3$. For the model parameters of section $2 \mathrm{c}$, the solution develops a self-sustained decadal signal, with a primary peak at $12.8 \mathrm{yr}$ and a secondary one at $6.4 \mathrm{yr}$, which, according to (11c), is necessarily generated by extraequatorial processes in the North Pacific $\left(y>12^{\circ} \mathrm{N}\right)$. For convenience, we refer to this solution as the main run. We first describe the response of the main run at midlatitudes, identifying the processes that maintain it (section 4a). Then, we discuss its equatorial response, which must be remotely forced by processes poleward of $12^{\circ} \mathrm{N}$ (section $4 \mathrm{~b}$ ). Finally, we report the influences of stochastic forcing in solutions with selfsustained and damped decadal modes (section 4c).

\section{a. Midlatitude response}

\section{1) DESCRIPTION}

Figure 5 plots sea level anomalies $(\Delta d)$ over half of the primary cycle. A striking characteristic is the westward propagation north of $25^{\circ} \mathrm{N}$. At $\theta=0^{\circ}$ and $45^{\circ}$, a region of negative $\Delta d$ develops in the northeast Pacific that first strengthens locally and then expands westward. It continues to propagate westward throughout the second half of the cycle, as illustrated by the negative anomalies in the figure. Near the western boundary, the anomaly strengthens and divides into two parts. The southern one continues to propagate westward and to weaken, and the northern one first intensifies in a region centered near $43^{\circ} \mathrm{N}, 160^{\circ} \mathrm{E}$, before shifting northward and dissipating sometime after $\theta=360^{\circ}$.

Figure 5 also plots the layer-1 flow-field anomalies $(\Delta \mathbf{v}$, arrows). The $\Delta d$ contours are approximate geostrophic streamlines for the model's layer-1 flow. Throughout most of the basin, the currents tend to be parallel to $\Delta d$ contours, indicating that they are largely geostrophic. There are also ageostrophic currents, the most prominent examples being the southeastward flow across $\Delta d$ contours in the $\theta=0^{\circ}$ and $45^{\circ}$ panels, a consequence of anomalous Ekman drift.

Figure 6 plots the corresponding evolution of $\Delta T_{1}$. It has a more complicated structure than $\Delta d$, likely because $T_{1}$ is affected by both ocean dynamics (advection and convection) and surface heat fluxes. Moreover, the relationships among $\Delta T_{1}, \Delta d$, and $\Delta \mathbf{v}_{1}$ change in different regions. For example, in the eastern and central North Pacific, the strong northward current between regions of positive and negative $\Delta d$ appears to generate warm $\Delta T_{1}$ by advection. In contrast, the large area of $\operatorname{cool} \Delta T_{1}$ in the eastern subtropics from $\theta=90^{\circ}$ to $180^{\circ}$ does not seem to be determined by advection, $\Delta \mathbf{v}_{1}$ there being much weaker. We infer that $\Delta T_{1}$ there is instead determined by surface fluxes, an idea that is confirmed in section $4 \mathrm{a}(2)$. Finally, sometimes $\Delta d$ appears to be centered on $\Delta T_{1}$ regions, and $\Delta \mathbf{v}_{1}$ circulates around them, a result of the factor of $T_{1}-T_{4}$ in (20). This situation is particularly clear for the northward-shifting anomaly along the western boundary.

Figure 6 also plots the wind anomaly ( $\Delta \tau \boldsymbol{\tau}$, arrows). Its time evolution consists primarily of large-scale circulations that form in the northeast Pacific, expand locally, and then shift westward. For example, the anticyclone that forms in the far northeastern corner of the basin at $\theta=0^{\circ}$ expands southward and strengthens from $\theta=45^{\circ}$ to $135^{\circ}$. As indicated by the cyclone in the panels, during the second half-cycle the anticyclone continues to move westward, shifts poleward, and fi- 

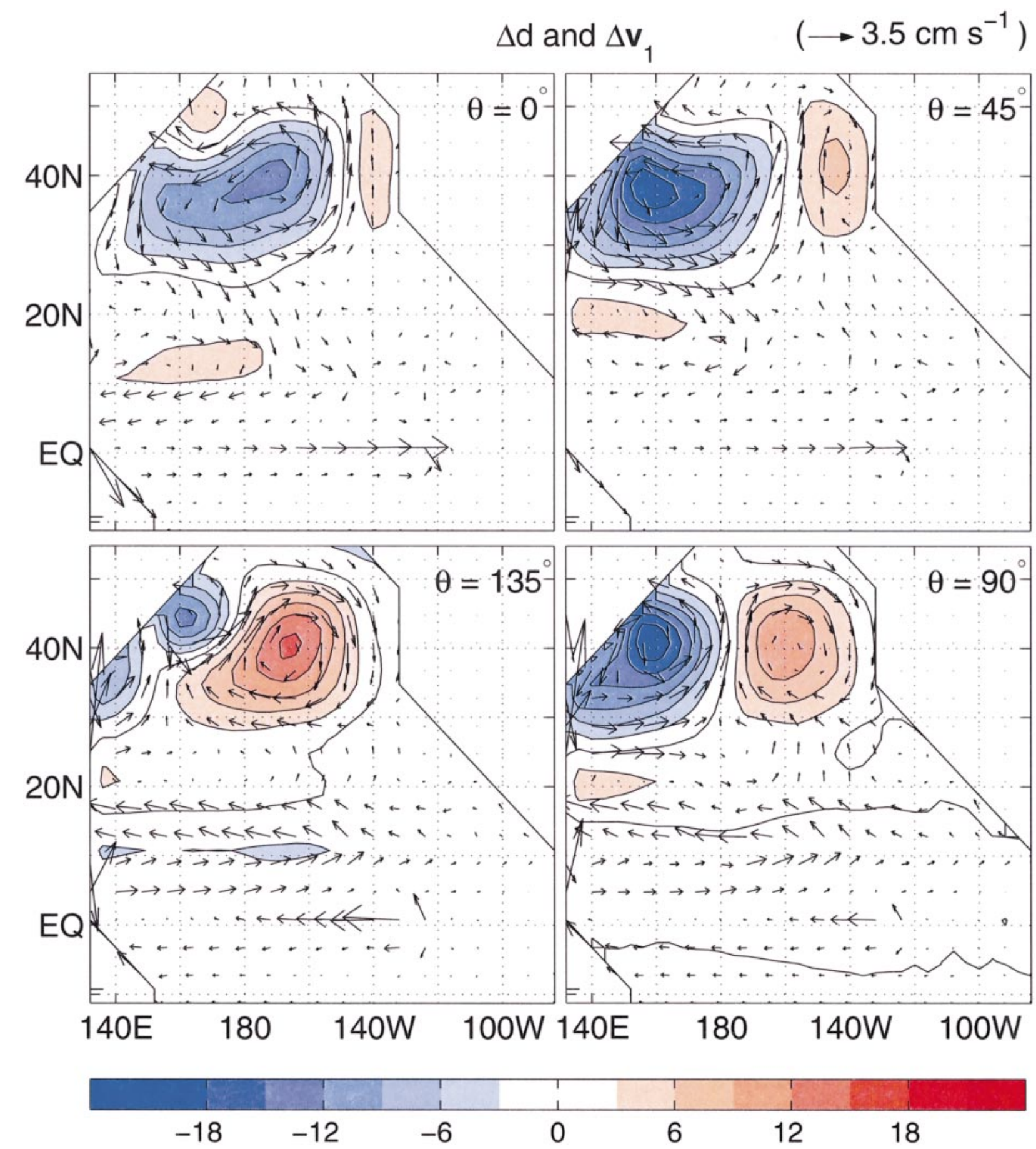

Fig. 5. Phase ( $\theta$ ) evolution of $\Delta d$ (contours) and $\Delta \mathbf{v}_{1}$ (vectors) for the decadal solution. Units for $\Delta d$ are $1 \mathrm{~cm}$.

nally moves out of the basin in the northwest corner. A comparison of Figs. 2 and 6 shows that the westward shift is associated with a switching from SVD4 to SVD3: SVD4 dominates $\Delta \boldsymbol{\tau}$ at $\theta=45^{\circ}$, SVD3 is strongest at $\theta=135^{\circ}$, and thereafter the negative of SVD4 emerges, allowing the westward movement of the anticyclone to continue. Note in Fig. 6 that the winds are quite strong in the subtropics and even extend into the Tropics. As we shall see, these winds are important for generating EDV in the solution.

A comparison of $\Delta \tau, \Delta d$, and $\Delta T_{1}$ maps suggests that the ocean responds to $\Delta \boldsymbol{\tau}$ in two prominent ways. The $\Delta d$ field clearly responds to the Ekman pumping associated with this forcing, with anticyclones (cyclones) 


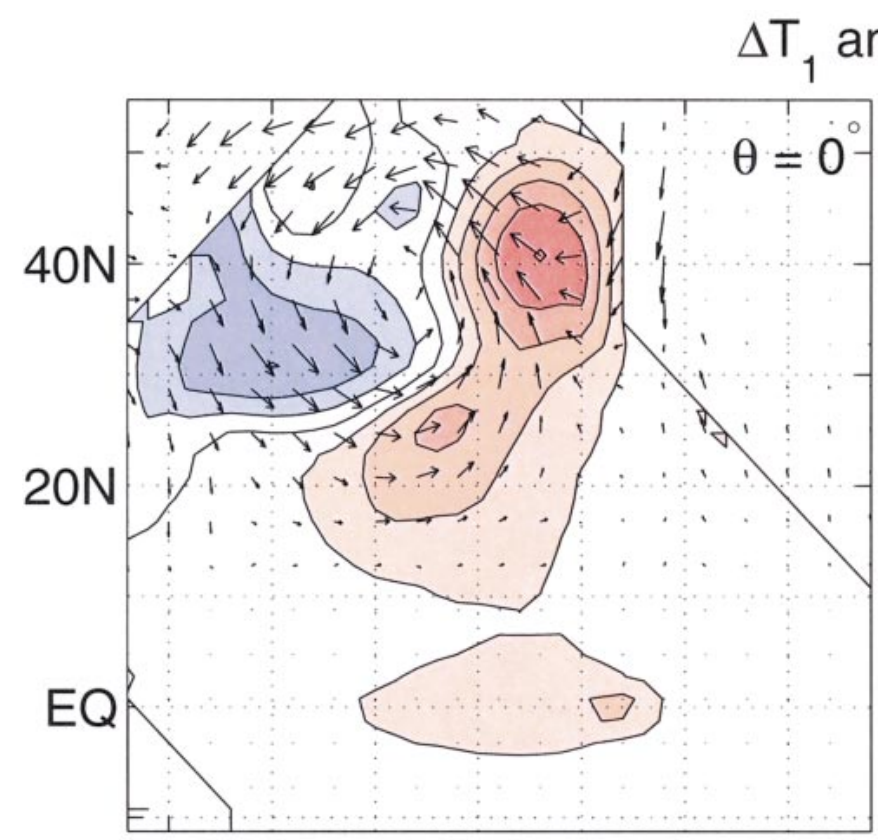
$\left(\rightarrow 0.038 \mathrm{~N} \mathrm{~m}^{-2}\right)$
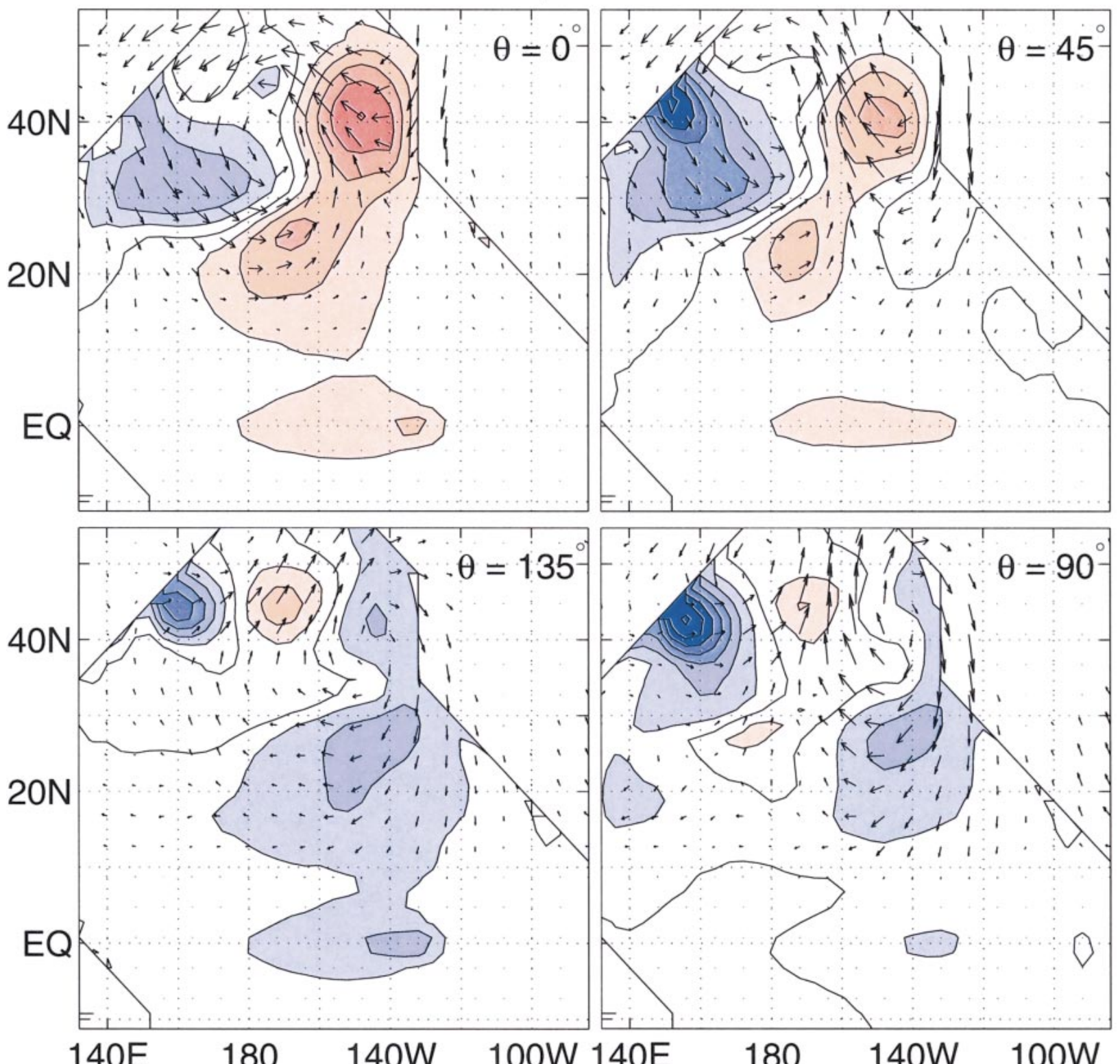

140E $180 \quad 140 W \quad 100 W$ 140E 180 140W $100 W$

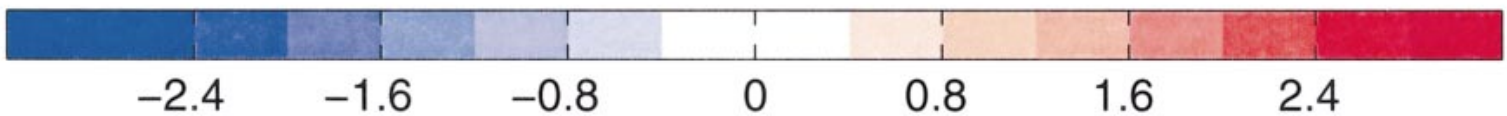

FIG. 6. Phase $(\theta)$ evolution of $\Delta T_{1}$ (contours) and $\Delta \tau$ (vectors) for the decadal solution. Units for $\Delta T_{1}$ are $1^{\circ} \mathrm{C}$.

being roughly collocated with regions of positive (negative) $\Delta d$. In the eastern and central subtropics, cold (warm) $\Delta T_{1}$ corresponds to $\boldsymbol{\tau}$ anomalies that tend to strengthen (weaken) the northeast trade winds, suggesting that they may result from changes to the surface heat flux caused by $\Delta W$.

All the preceding properties are consistent with the following scenario for the cause of the solution's decadal oscillation. Suppose initially that there is a $\Delta T_{1}$ in the northwest Pacific that forces $\Delta \boldsymbol{\tau}$ through atmospheric teleconnections in the northeast Pacific. These anomalous winds generate $\Delta d$ locally via Ekman pumping and excite Rossby waves that subsequently propagate across the basin. The Rossby waves are strengthened by the westward shift of $\Delta \boldsymbol{\tau}$ and eventually cause a basin-wide adjustment of $\Delta d$ and $\Delta \mathbf{v}_{1}$. This adjustment alters $\Delta T_{1}$ 


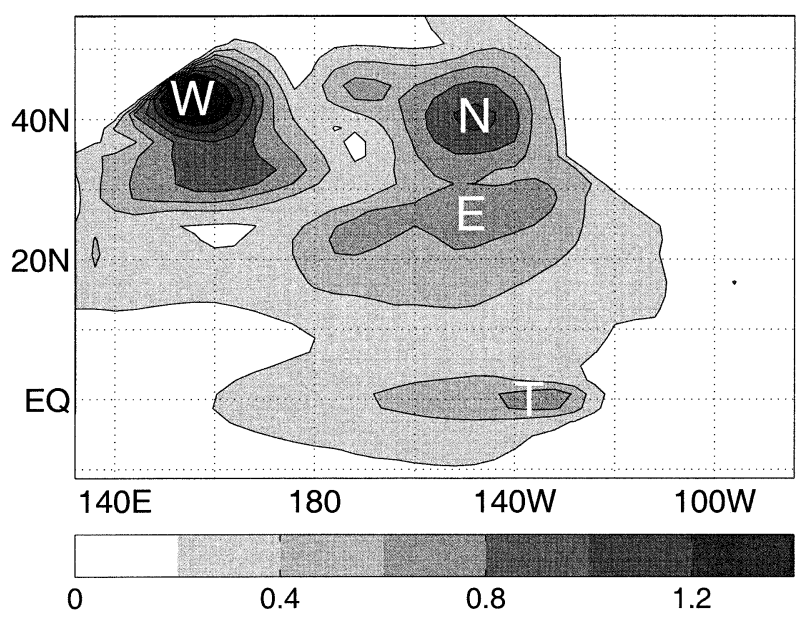

FIG. 7. Standard deviation of $\Delta T_{1}$ variability for the decadal solution averaged over one oscillation. Units are $1^{\circ} \mathrm{C}$.

in the northwest Pacific through advection, particularly in the western boundary current, and through atmospheric teleconnections it generates a $\Delta \tau$ in the northeast region of the opposite sign. The analyses reported in the next two sections support this scenario. In addition, they point toward the importance of ocean-atmosphere coupling in the eastern subtropics.

Recall that the model was not able to generate a decadal mode when SVD4 was omitted from the empirical atmosphere, that is, with $N=3$ in (7). To check the sensitivity of this property to the types of SVDs used, we constructed the empirical model using the $J=3$ wintertime SVDs defined in section 2c(1)ii. For the choices for $N, \theta_{k}$, and $\phi_{k}$ listed in section $2 \mathrm{c}(1) \mathrm{v}$, the resulting coupled solution was almost unchanged from the one described here. For reasons that are not clear, however, the model was also able to develop a decadal oscillation when $N=3$, pointing toward the critical importance of SVD3, rather than SVD4, in the dynamics of the decadal mode.

\section{2) Thermodynamics}

Figure 7 shows the standard deviation of $\Delta T_{1}$ averaged over one period of the oscillation. Relative maxima are in the northwest $\left(43^{\circ} \mathrm{N}, 156^{\circ} \mathrm{E}\right)$, the subtropical northeast $\left(31^{\circ} \mathrm{N}, 144^{\circ} \mathrm{W}\right)$, the midlatitude northeast $\left(41^{\circ} \mathrm{N}, 144^{\circ} \mathrm{W}\right)$, and the Tropics $\left(0^{\circ} \mathrm{N}, 135^{\circ} \mathrm{W}\right)$. Hereafter, we use the labels $\mathrm{W}, \mathrm{E}, \mathrm{N}$, and T to refer to $16^{\circ}$ longitude by $8^{\circ}$ latitude boxes centered on each of these points. Since $\Delta \tau$ is forced by $\Delta T_{1}$ outside the Tropics, the first three boxes are key regions to look for oceanto-atmosphere feedbacks. Here, we carry out analyses to determine the processes that cause $\Delta T_{1}$ in each of them.

Subtracting the time average of (1) from (1) itself, yields an equation for the $T_{1}$ anomaly field,

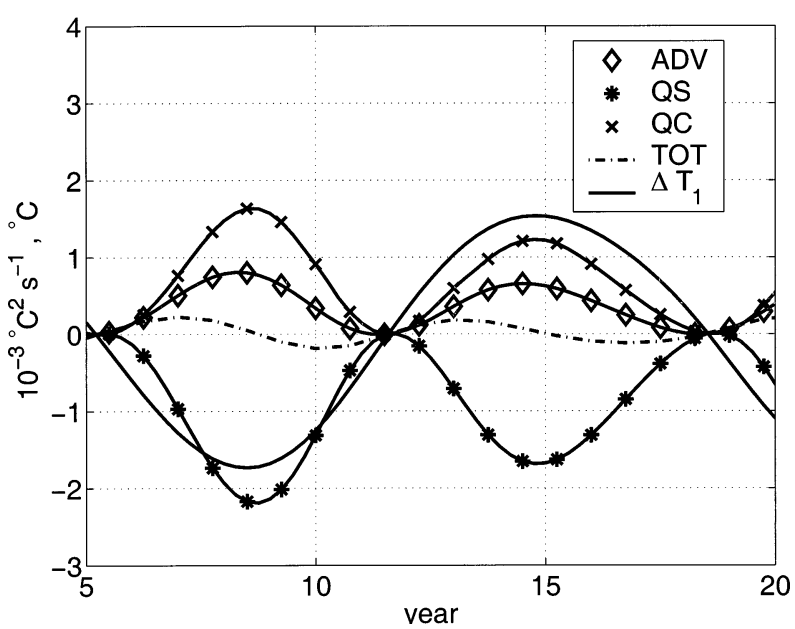

FIG. 8. Time series of dominant terms from Eq. (22) averaged over region $\mathrm{W}$. The curves indicate total advection (ADV), total surface heat flux (QS), convective overturning (QC), the sum over all tendency terms (TOT), and $\Delta T_{1}$.

$$
\Delta T_{1 t}=\sum_{j=1}^{g} \Delta q_{j}
$$

where each $q_{j}$ is one of the heating terms on its righthand side, $\Delta q_{j} \equiv q_{j}-\left\langle q_{j}\right\rangle$ and $g$ is the number of terms. Multiplying (21) by $\Delta T_{1}$ yields

$$
\frac{1}{2}\left[\left(\Delta T_{1}\right)^{2}\right]_{t}=\sum_{j=1}^{g} \Delta T_{1} \Delta q_{j}
$$

The positive (negative) terms on the right-hand side are responsible for the instantaneous growth (decay) of $T_{1}$ anomalies regardless of their sign.

Figure 8 plots the dominant terms in Eq. (22) averaged over region $\mathrm{W}$, showing advection (ADV), total surface heat flux (QS), and convective overturning (QC). Interestingly, QS acts to damp $\Delta T_{1}$, so that ocean dynamics determine $\Delta T_{1}$. Indeed, both advection and convective overturning provide the positive feedback that amplifies $\Delta T_{1}$, consistent with the study of Schneider et al. (2002). Plots of terms in (21) (not shown) indicate that the convection is triggered by anomalous advection, with the anomalous currents preceding convection by 4-6 months, and that the switching mechanism (delayed negative feedback) for $\Delta T_{1}$ is also provided by anomalous advection. Calculation of the terms for region $\mathrm{N}$ (not shown) demonstrates that, as for region $\mathrm{W}, \mathrm{ADV}$ is the dominant growth mechanism with QS providing the decay, but there is no heat anomaly due to QC.

Figure 9 plots the dominant terms from Eq. (22) averaged over region $\mathrm{E}$, showing advection, total surface heat flux, and two parts of the latent heat flux, namely, the part due to $\Delta W$ (LHW) and the remainder due to $\Delta T_{1}$ (LHT). Integrated over one cycle, only QS provides a positive contribution, and so acts to amplify $\Delta T_{1}$ lo- 


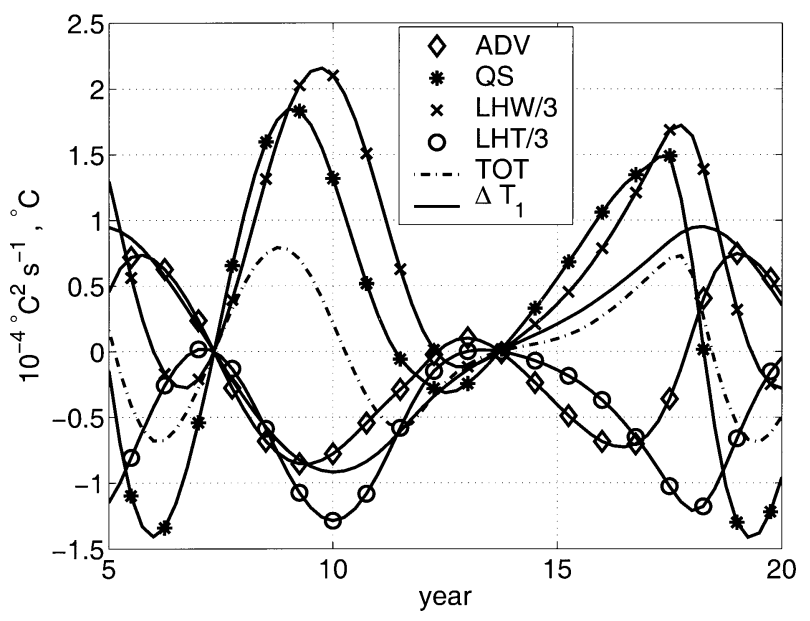

FIG. 9. Time series of dominant terms from Eq. (22) averaged over region $\mathrm{E}$. The curves indicate total advection (ADV), total surface heat flux $(\mathrm{QS})$, and the dominant terms that contribute to QS, namely, latent heat flux due to $\Delta W$ (LHW) and the rest of the latent heating due to $\Delta T_{1}$ (LHT), the sum over all tendency terms (TOT), and $\Delta T_{1}$.

cally; moreover, the positive contribution results from LHW, a result noted by KMK. Conversely, the other terms (as well as LHW for part of the cycle) are negative when integrated over one oscillation cycle, and so tend to dampen it. Near region E, then, local air-sea feedback via LHW intensifies $\Delta T_{1}$, whereas ocean dynamics (ADV) tends to dampen it. In a similar analysis of (21), the term analogous to LHT is also dominant when $\Delta T_{1}$ $=0$ (not shown), an indication that the switching mechanism arises from remotely forced winds.

\section{3) OCEAN-ONLY SOLUTIONS}

To explore the influences of local and remote forcing in the main run, we obtained solutions to a series of model runs where the ocean model was forced by versions of $\Delta \tau$ saved from the coupled run. In one of those tests, we forced the model using $\Delta \tau$ only east of $160^{\circ} \mathrm{W}$, setting $\Delta \tau$ to zero west of $160^{\circ} \mathrm{W}$. Figure 10 illustrates the evolution of $\Delta d$ for this run over half of a cycle. Consistent with the coupled run (Fig. 5), the forced response develops an anticyclonic gyre in the eastern ocean that subsequently propagates westward. One obvious difference between the forced and coupled solutions is that $\Delta d$ is considerably weaker in the western ocean in the ocean-only solution. Another is that the westward propagation is a bit faster in the coupled solution. This can be seen in the northward current between positive and negative $\Delta d$ regions, which is shifted farther to the west in the coupled solution. We conclude that oceanic Rossby waves, generated by wind curl in the northeastern ocean, are important for causing the westward propagation in the coupled solution. In addition, wind forcing in the north-central and northwestern regions maintains and strengthens the waves, particularly because of the simultaneous westward shift of the forcing.

\section{4) MASKED RUNS}

To determine the locations of key ocean-to-atmosphere feedbacks, we obtained a series of coupled runs with feedbacks suppressed in specific regions by adjusting $\theta_{k}$ and $\phi_{k}$ in (11c). Here, we report solutions in which the basin is divided into quadrants by the lines $x=170^{\circ} \mathrm{W}$ and $y=30^{\circ} \mathrm{N}$, and either $\Delta T_{1}, \Delta \tau$, or both are masked in one or more quadrants.

A solution with $\Delta T_{1}$ masked in the northeast and southwest quadrants still oscillates provided that $\phi_{o}$ is increased to 1.5. In contrast, solutions with $\Delta T_{1}$ masked separately in the southeast and northwest quadrants never oscillate regardless of the value of $\phi_{o}$. Expanding upon these results, we obtained a test solution with $\Delta T_{1}$ masked in the northeast and southwest quadrants and with $\Delta \boldsymbol{\tau}$ masked in both western quadrants. With $\phi_{o}$ increased to 1.5 , the solution oscillates with the same period as the main run but with a weaker amplitude; when $\phi_{o}$ is increased to 2.5 , the solution also has a similar amplitude. Figure 11 shows the evolution of $\Delta d$ and $\Delta \mathbf{v}_{1}$ over one-half of the decadal oscillation for the latter solution, and the similarity to Fig. 5 is striking; moreover, it also reproduces $\Delta T_{1}$ from the coupled run just as well (not shown).

These results suggest that the solution in Fig. 11 captures the essential physics of the decadal oscillation in the main run. In particular, it points toward the importance of ocean-to-atmosphere coupling in the northwest midlatitudes and northeast subtropics. We interpret the coupling in the former region to represent an influence of SST on the location of the storm track, which causes anomalous atmospheric circulation in the northeast midlatitudes though atmospheric teleconnections. Its necessity is consistent with the prior observational and modeling work indicating that northwest SST anomalies are related to wind anomalies in the northeast (see section 1 and Yulaeva et al. 2001). We interpret coupling in the latter region to represent the ability of subtropical SST anomalies to maintain the atmospheric circulation in the northeast and to broaden it southward into the subtropics, consistent with the analysis of atmospheric wave-activity flux reported by Nakamura and Yamagata (1999). The potential importance of coupling in the northeast subtropics has been noted by others (e.g., Nakamura and Yamagata 1999; Nakamura and Izumi 2002; KMK; F.-F. Jin 2001, personal communication). Indeed, KMK were able to obtain a decadal oscillation without any coupling in the northwest quadrant, likely a consequence of their coupling coefficients $c_{k}$ being considerably larger than ours.

\section{b. Equatorial response}

Figure 6 shows a strong $\Delta T_{1}$ signal near the equator, with a maximum amplitude of about $1^{\circ} \mathrm{C}$ near $130^{\circ} \mathrm{W}$. 


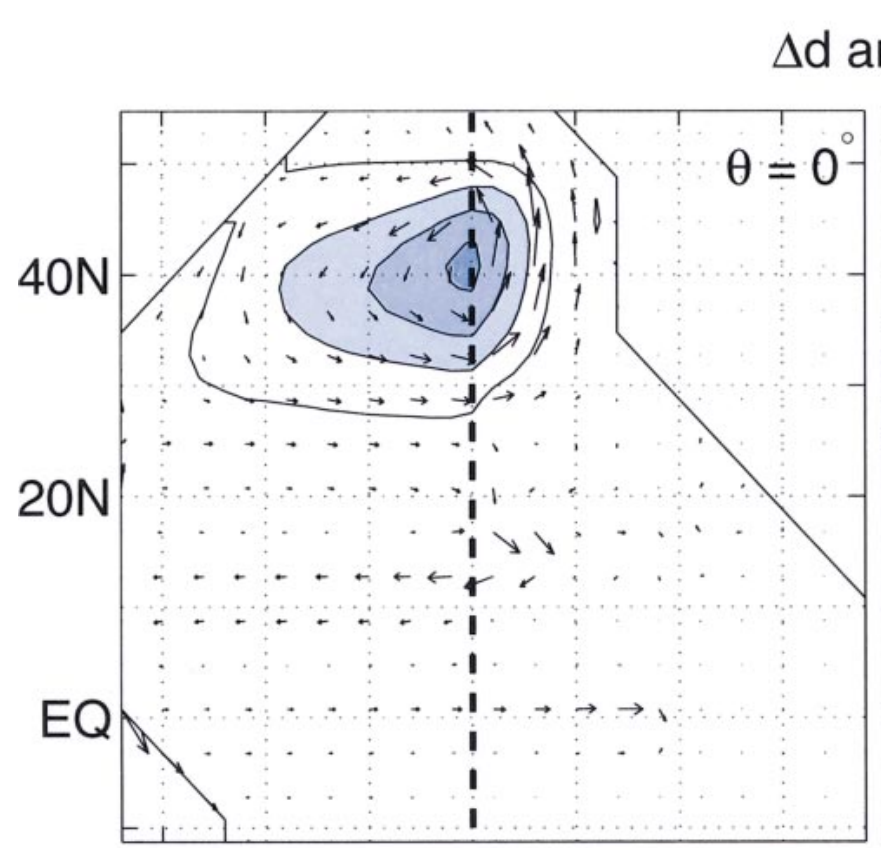

$\Delta \mathrm{d}$ and $\Delta \mathbf{v}_{1} \quad\left(\rightarrow 3.5 \mathrm{~cm} \mathrm{~s}^{-1}\right)$
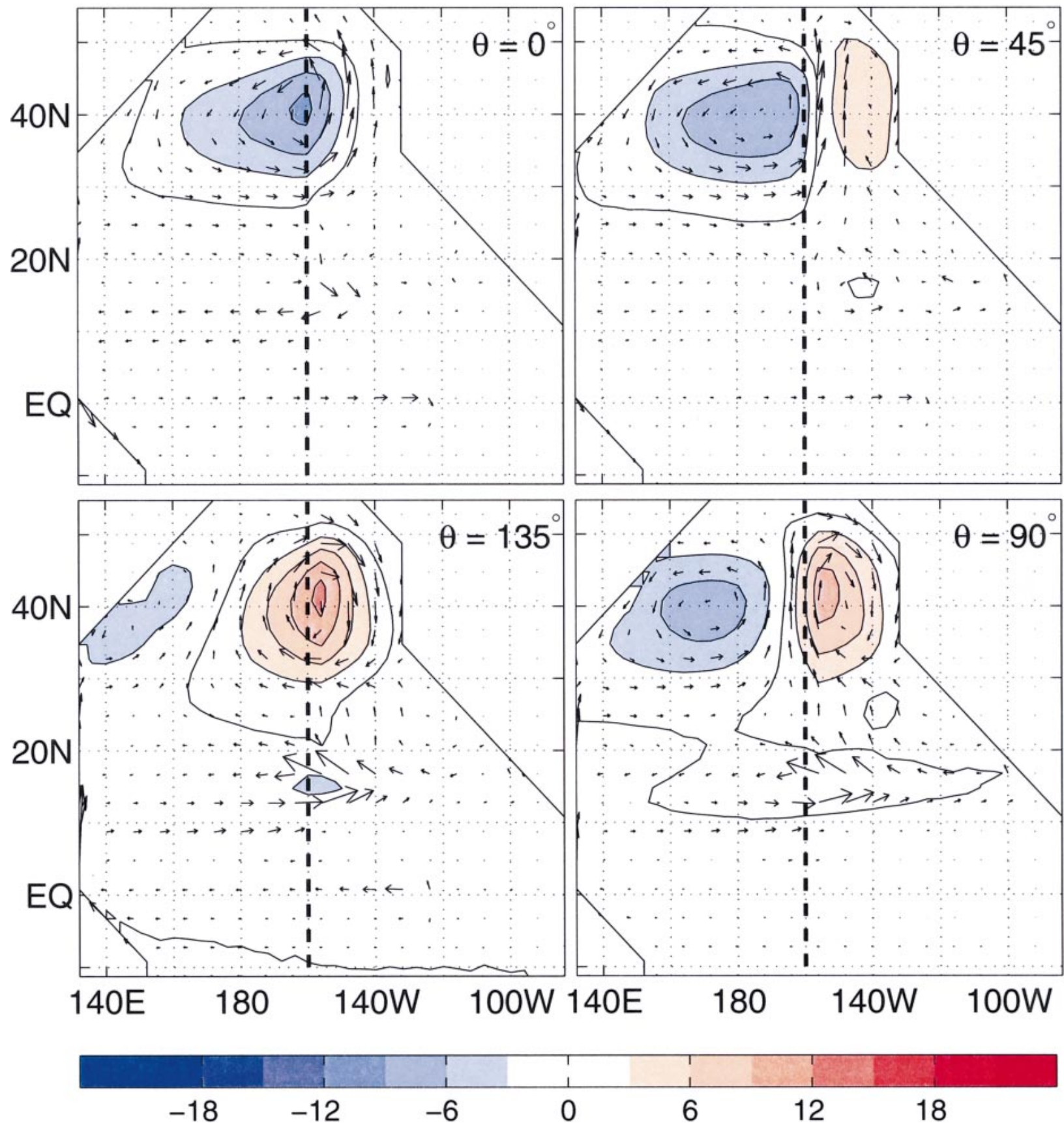

FIG. 10. Phase $(\theta)$ evolution of $\Delta d$ (contours) and $\Delta \mathbf{v}_{1}$ (vectors) for the decadal solution with air-sea feedback east of $180^{\circ}$ (dashed line) suppressed. Units for $\Delta d$ are $1 \mathrm{~cm}$.

Since $\Delta \boldsymbol{\tau}$ is suppressed near the equator by Eq. (11c), this equatorial variability must be caused by oceanic teleconnections forced north of $12^{\circ} \mathrm{N}$. Here, we demonstrate that the teleconnection occurs through changes in the strength of various branches of the North Pacific STC, and report the sensitivity of solutions to $\Delta \tau^{x}$ along the subduction cutoff latitude, $y_{d}=18^{\circ} \mathrm{N}$, and to the value of $y_{d}$ itself.

Figure 12a shows anomalies of $M_{1}\left(y_{d}\right)$ (solid curve with $\times), M_{2}\left(y_{d}\right)$ (solid curve with $\bigcirc$ ), $E\left(y_{d}\right)$ (thick dashed curve), the upwelling-transport anomaly between layers 1 and 2 near the equator $\mathcal{W}$ (dashed curve), 

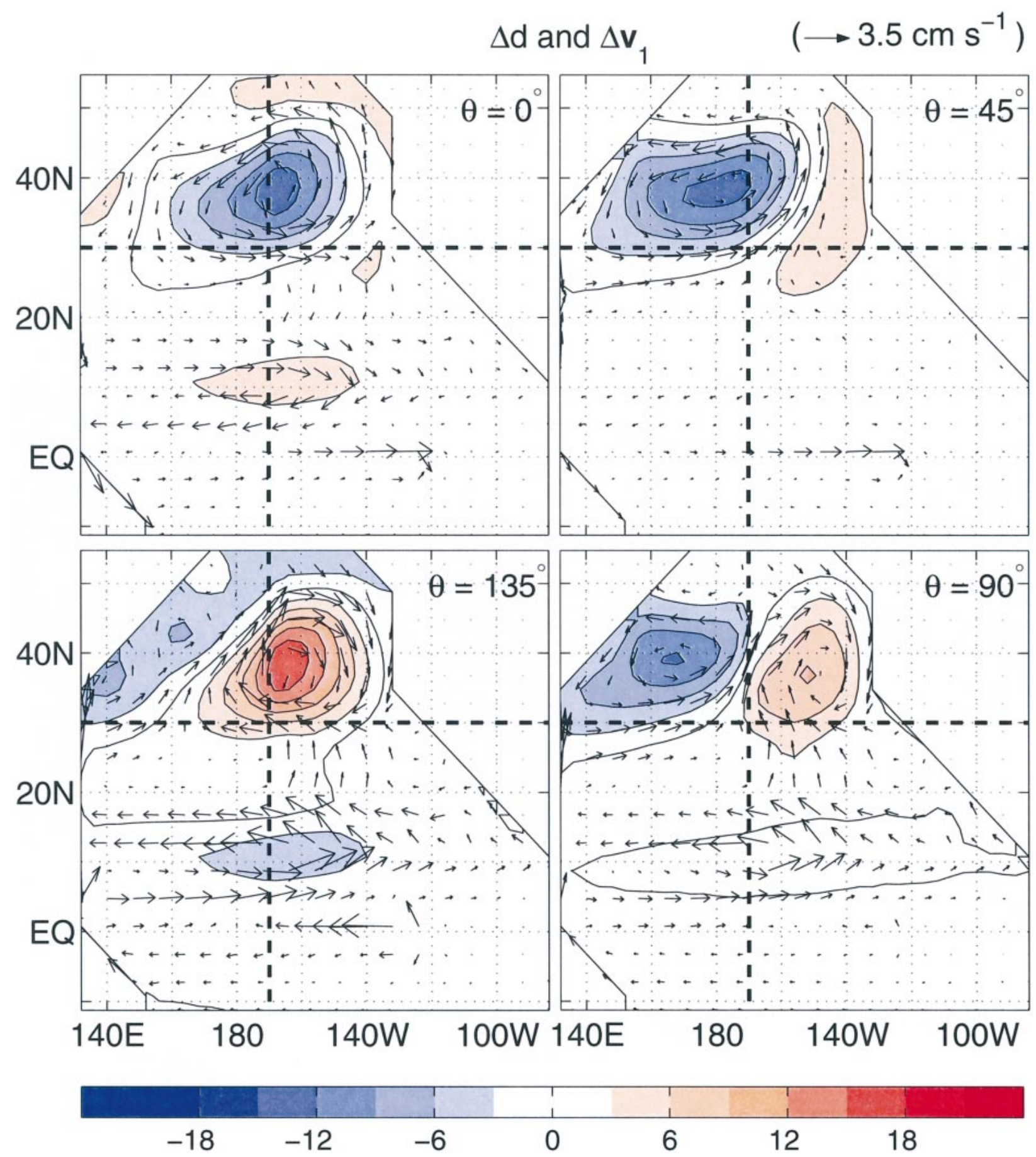

FIG. 11. Phase ( $\theta)$ evolution of $\Delta d$ (contours) and $\Delta \mathbf{v}_{1}$ (vectors) for the coupled run with air-sea feedbacks in the northeast and southwest quadrants suppressed and $\Delta \tau$ masked to the west of $180^{\circ}$. Units for $\Delta d$ are $1 \mathrm{~cm}$. Dashed lines denote quadrant borders.

and $\Delta T_{1}$ averaged in the Niño-3.5 region $\mathcal{T}_{1}$ (solid curve) for the main run. The $\mathcal{W}$ curve covaries with $\mathcal{T}_{1}$, indicating that $\mathcal{T}_{1}$ results largely from changes in the amount of cool water that upwells into layer 1. An analogous plot for $\mathcal{T}_{2}$ (the average of $\Delta T_{2}$ in the Niño-3.5 region) has an amplitude of only about $0.1^{\circ} \mathrm{C}$, so that $\mathcal{T}_{1}$ is not caused by the advection and upwelling of subsurface temperature anomalies, as in the $\mathrm{Gu}$ and Philander (1997) hypothesis. The $\Delta M_{1}\left(y_{d}\right)$ curve has a similar shape to both $\Delta E\left(y_{d}\right)$ and $\mathcal{W}$, and leads $\mathcal{W}$ by about 2 yr. These properties suggest that both $\mathcal{W}$ and $\mathcal{T}_{1}$ are driven by changes in $M_{1}\left(y_{d}\right)$ and hence the strength of 


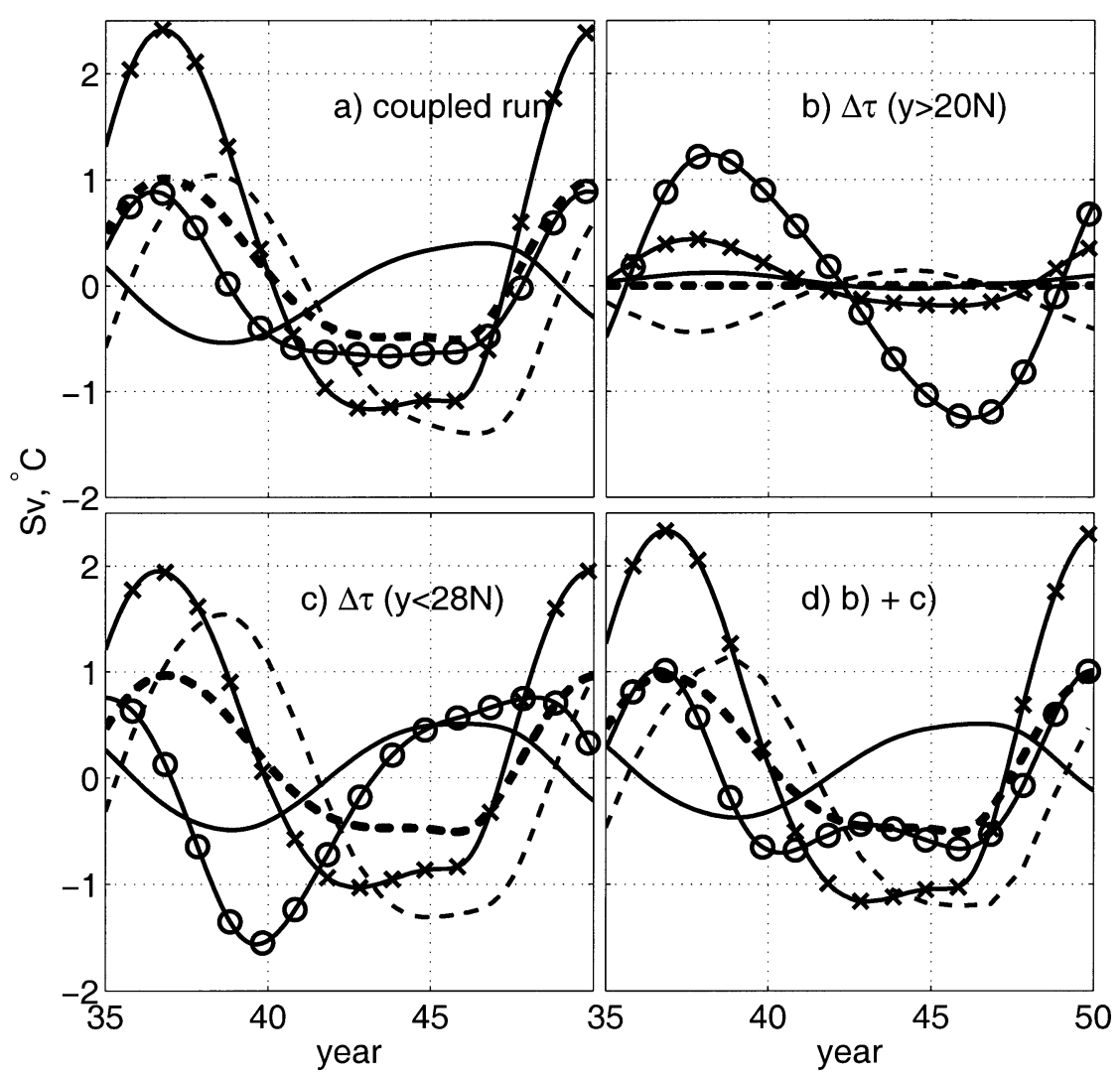

FIG. 12. Time series of anomalies of $M_{1}\left(y_{d}\right)(\times), M_{2}\left(y_{d}\right)(\bigcirc), E\left(y_{d}\right)$ (thick dashed), $\mathcal{W}$ (dashed), and $\mathcal{T}_{1}$ (solid). Results shown are for (a) the decadal solution, (b) an ocean-only solution forced by winds from the decadal solution confined poleward of $20^{\circ} \mathrm{N}$, (c) an ocean-only solution forced by winds at full strength equatorward of $20^{\circ} \mathrm{N}$, and (d) the sum of the curves in (b) and (c). Units for $M_{1}, M_{2}, E$, and $\mathcal{W}$ are $1 \mathrm{~Sv}\left(1 \mathrm{~Sv} \equiv 10^{6} \mathrm{~m}^{3} \mathrm{~s}^{-1}\right)$, and for $\mathcal{T}_{1}$ are $1^{\circ} \mathrm{C}$.

the North Pacific STC, as proposed by KMK. Transport $\Delta M_{1}\left(y_{d}\right)$ also has a similar shape to $\Delta M_{2}\left(y_{d}\right)$, a property that is not consistent with quasi-steady changes in the STC for which $\Delta M_{1}\left(y_{d}\right) \approx-\Delta M_{2}\left(y_{d}\right)$. As discussed next, this difference exists because the response is not at all quasi-steady, involving the propagation of Rossby waves about the basin.

To isolate the part of the wind field that drives the tropical circulation, we carried out two ocean-only runs, one forced by winds saved from the coupled run that were confined poleward of $y_{d}$ (extratropical winds; Fig. $12 \mathrm{~b}$ ) and at their full strength equatorward of $y_{d}$ (tropical winds; Fig. 12c). Given the latitudinal resolution of the atmospheric grid $\left(\Delta y=4^{\circ}\right)$, this separation was accomplished by linearly ramping the winds from $20^{\circ}-28^{\circ} \mathrm{N}$ to zero when $y>28^{\circ} \mathrm{N}\left(y<20^{\circ} \mathrm{N}\right)$ for the tropical (extratropical) winds. Figure 12d plots the sum of curves from the two forced runs; they closely track those of the coupled run, demonstrating that the STC variability responds nearly linearly to the winds.

A comparison of the curves in Figures $12 \mathrm{a}-\mathrm{c}$, demonstrates that most of the equatorial response in the coupled solution is driven by tropical winds, the exception being for $\Delta M_{2}\left(y_{d}\right)$. In particular, note that the extratropical winds force relatively weak $\mathcal{W}$ and $\mathcal{T}_{1}$ with opposite signs to those in the main run. In addition, when the extratropical winds are excluded (Fig. 12c), $\mathcal{W}$ lags $\Delta M_{1}\left(y_{d}\right)$ by approximately $2 \mathrm{yr}$ but leads $-\Delta M^{2}\left(y_{d}\right)$ by about $1 \mathrm{yr}$. This sequence indicates that winds across $y_{d}$ drive $\Delta M_{1}\left(y_{d}\right)$ that drives $\mathcal{W}$, which in turn spins up a $\Delta M_{2}\left(y_{d}\right)$ of the opposite sign to $\Delta M_{1}\left(y_{d}\right)$, consistent with the conclusions of Klinger et al. (2002). This relationship is unclear in the coupled run due to $\Delta M_{2}\left(y_{d}\right)$ also being forced by extratropical winds.

Recall from the discussion of (3) that the STC strength in steady solutions depended on $E$ and hence on $\Delta \tau^{x}$ along the subduction latitude $y_{d}$. To test the sensitivity of solutions to $\Delta \tau^{x}\left(y_{d}\right)$, we obtained a test run with $\phi_{k}=S\left(y-19^{\circ}\right)$ so that $\Delta \boldsymbol{\tau}$ was set to zero equatorward of $19^{\circ} \mathrm{N}$ and $\Delta \tau^{x}\left(y_{d}\right)=0$. With $\phi_{o}$ unchanged, the resulting solution developed an oscillation with the same period but with a considerably weaker amplitude than in the main run, suggesting that $\Delta T_{1}$ from $12^{\circ}-19^{\circ} \mathrm{N}$ plays a role in the oscillation dynamics. Indeed, $\Delta T_{1}$ is large in this region in the main run, and it projects significantly onto both SVD3 and SVD4 temperature patterns. Increasing $\phi_{o}$ by $30 \%$, however, resulted in a decadal oscillation with the same amplitude 
and timescale as the main run, indicating that $\Delta T_{1}$ in this region is not of critical importance. In this run, however, the peak-to-peak maximum amplitude of $\mathcal{T}_{1}$ at the equator reduced from $1^{\circ}$ to $0.2^{\circ} \mathrm{C}$ (similar to the weak $\mathcal{T}_{1}$ for the midlatitude-forced solution in Fig. 12b). We conclude that, consistent with steady-state theory, $\Delta \tau^{x}\left(y_{d}\right)$ does affect the STC strength and $\mathcal{T}_{1}$ significantly.

Finally, we obtained a solution with $y_{d}$ increased from $18^{\circ}$ to $25^{\circ} \mathrm{N}$. This solution had a decadal oscillation with the same structure and period as the main run, and $\mathcal{T}_{1}$ also did not change much. The reason for this similarity is that $E\left(y_{d}\right)$ is not much changed, a consequence of $\Delta \tau^{x}$ being stronger at $25^{\circ} \mathrm{N}$ and therefore compensating for the increase in $f$.

\section{c. Damped mode and stochastic forcing}

Solutions are sensitive to the value of $\phi_{o}$. For example, when $\phi_{o}$ is increased to 1.4 the amplitude of the oscillation is $70 \%$ larger. Conversely, when it is reduced to 1.2 the oscillation rapidly decays away and the solution adjusts to a steady state.

To investigate the nature of the coupled system when the mode is damped, we obtained a series of solutions with $\phi_{o}=1.2$, including additional forcing by the SVD1 wind pattern (Fig. 2) with an amplitude such that $\mathcal{T}_{1}$ is approximately equal to $1^{\circ} \mathrm{C}$ and periods $P$ varying from 2 to $24 \mathrm{yr}$. After an initial adjustment, the solutions all oscillated with a period $P$, with the largest amplitude occurring when $P=16 \mathrm{yr}$, somewhat longer than the period of the self-sustained mode $(12.8 \mathrm{yr})$ due to the damping. In addition, the solution with $P=24 \mathrm{yr}$ developed a secondary peak at $P / 2$, a result of the excitation of the model's decadal mode by nonlinearities. These properties indicate that the system is a weakly nonlinear, damped oscillator, in which the damped mode responds resonantly to the forcing.

There is considerable interest at present regarding the possible generation of midlatitude decadal variability by stochastic forcing (e.g., Saravanan and McWilliams 1997; Moore 1999). We examined the influence of such forcing in our model by including it as an externally prescribed wind stress anomaly $\Delta \boldsymbol{\tau}^{\prime}$, as outlined in section $2 \mathrm{c}(3)$. With $\Delta \boldsymbol{\tau}^{\prime}$ included and $\phi_{o}=1.3$, the selfsustained oscillation remained and the peak at a 13.5yr period continued to exceed the $99 \%$ significance level based on a first-order autoregressive process (AR1) null hypothesis; however, the amplitude of the decadal spectral peaks of $\Delta T_{1}$ in regions $\mathrm{E}$ and $\mathrm{W}$ decreased to $20 \%$ of their values without $\Delta \boldsymbol{\tau}^{\prime}$, apparently because the stochastic forcing altered $\Delta T_{1}$ enough to weaken the coupling associated with SVD3 and SVD4 significantly. With $\Delta \tau^{\prime}$ and $\phi_{o}=1.2$, the spectrum of $\Delta T_{1}$ in regions $\mathrm{E}$ and $\mathrm{W}$ became indistinguishable from an AR1 spectrum calculated with the same variance and lag-1 autocorrelation as the model output. In our model, then,

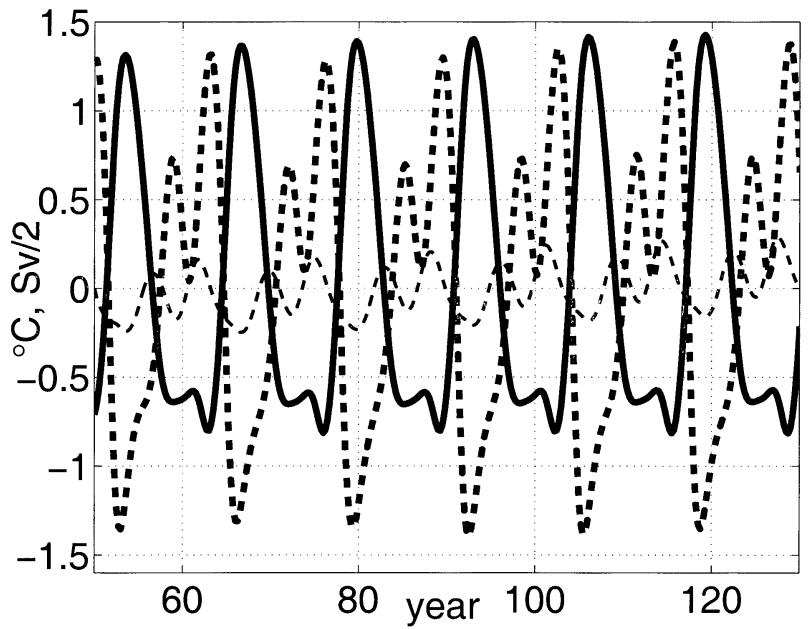

FIG. 13. Time series of $\mathcal{T}_{1}$ (thick dashed), NPI (thin dashed), and $E\left(y_{d}\right)$ (solid) in the coupled run with self-sustained interannual $\left(\phi_{1}\right.$ $=1.3)$ and decadal $\left(\phi_{o}=1.3\right)$ oscillations. Units for temperature and transport are $1^{\circ} \mathrm{C}$ and $0.5 \mathrm{~Sv}$.

the addition of stochastic forcing tends to inhibit, rather than to enhance, decadal variability.

\section{Solutions with both modes}

In this section, we report solutions when both tropical and extratropical feedbacks are allowed, that is, with $\phi_{k}$ and $\theta_{k}$ specified as in Eqs. (11). These solutions are able to develop both interannual and decadal oscillations. The basic structure and dynamics of each oscillation are unchanged from those discussed in sections 3 and 4 , so here we focus on interactions between the two signals.

Figure 13 shows the temporal behavior of the coupled oscillation when $\phi_{o}=1.3$, plotting curves for $E\left(y_{d}\right)$, $\mathcal{T}_{1}$, and the North Pacific index (NPI, the average temperature anomaly in the region $29^{\circ}-55^{\circ} \mathrm{N}, 160^{\circ} \mathrm{E}-$ $\left.140^{\circ} \mathrm{W}\right)$. All three curves have both interannual and decadal variability. The structure and amplitude of $E\left(y_{d}\right)$ are very similar to those in the main run (Fig. 12a), showing only a weak influence of the interannual signal. In contrast, the interannual modulation of NPI, caused by atmospheric teleconnections from the Tropics, is large. (The amplitude of NPI is small because it straddles regions where $\Delta T_{1}$ has opposite signs. See Figs. 6 and 7.) Perhaps most striking, $\mathcal{T}_{1}$ is dominated by decadal variability, with one out of every three oscillations of the interannual mode being suppressed (reversed). The interannual and decadal signals are in fact phaselocked with a period ratio of 1:3, a property noted by KMK in their solutions with stronger midlatitude coupling. As discussed in section 4, this model EDV results entirely from STC transport variability.

When $\phi_{o}$ is reduced to 1.2 , the decadal oscillation is damped in the absence of tropical forcing (section 4c). When tropical feedback is allowed, however, atmospheric teleconnections from the Tropics are sufficient 


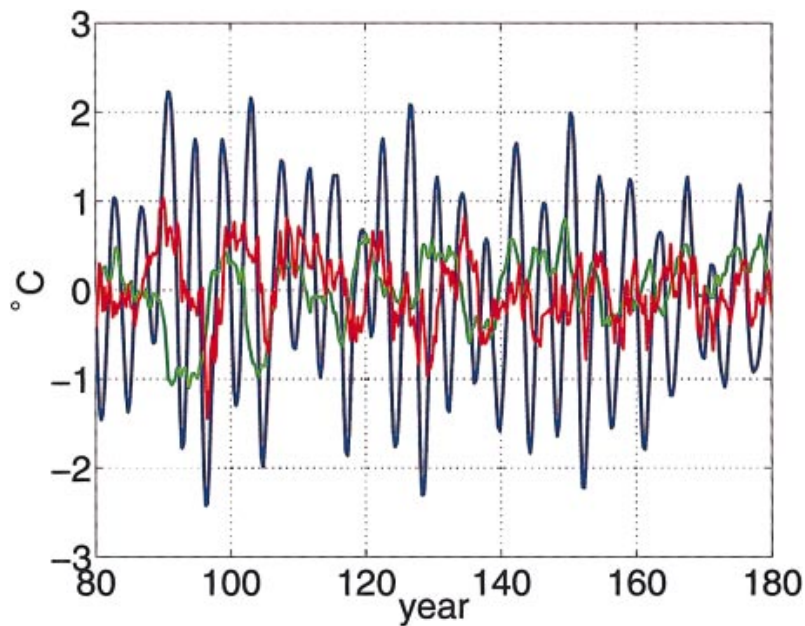

FIG. 14. Time series of $\mathcal{T}_{1}$ (blue), and temperature anomalies in regions $\mathrm{W}$ (green) and $\mathrm{E}$ (red) in the coupled run with self-sustained interannual $\left(\phi_{1}=1.3\right)$ and damped decadal $\left(\phi_{o}=1.2\right)$ oscillations and stochastic forcing. Units are $1^{\circ} \mathrm{C}$.

to maintain it, albeit with a smaller amplitude: NPI, $E\left(y_{d}\right)$, and $\mathcal{T}_{1}$ curves are similar in structure to those in Fig. 13 but their amplitude is smaller by about 33\%. Interestingly, the interannual and decadal signals are no longer precisely phase-locked, likely a result of the weakened decadal signal. As a result, $\mathcal{T}_{1}$ has a slowly varying beat pattern with a period longer than $100 \mathrm{yr}$.

Figure 14 illustrates the coupled solution when $\phi_{o}=$ 1.2 and with stochastic forcing by $\Delta \tau^{\prime}$, showing curves for $\mathcal{T}_{1}$ and temperature anomalies in regions $\mathrm{E}\left(\mathcal{T}_{E}\right)$ and $\mathrm{W}\left(\mathcal{T}_{W}\right)$. Consistent with the results in section $4 \mathrm{c}$, the decadal oscillation is much weaker, but it is still visible in all three curves. (Curves $\mathcal{T}_{E}$ and $\mathcal{T}_{W}$ actually have a larger amplitude than NPI in Fig. 13 because they are centered in regions where $\Delta T_{1}$ is of one sign and achieves a relative maximum.) In $\mathcal{T}_{E}$ and $\mathcal{T}_{W}$, the decadal signal and higher-frequency noise is most apparent. In $\mathcal{T}_{1}$, the decadal variability is much weaker than in Fig. 13 , so that it now appears as an irregular modulation of a strengthened interannual signal. Finally, Fig. 15 shows $\mathcal{T}_{1}, \mathcal{T}_{E}$, and $\mathcal{T}_{W}$ for a solution with stochastic forcing and $\phi_{o}=0$, for which there is no extratropical decadal mode. The interannual signal is now most apparent in the $\mathcal{T}_{E}$ and $\mathcal{T}_{W}$ curves, with no indication of a distinct decadal peak. In $\mathcal{T}_{1}$, the interannual signal is even stronger than in Fig. 13, and decadal variability occurs at longer periods.

For all these solutions, there is strong two-way coupling between the Tropics and extratropics. Suppose initially that a decadal signal is generated at midlatitudes (e.g., by forcing the model with the SVD3 wind anomaly pattern for some time). This signal is subsequently transmitted to the Tropics via oceanic teleconnections through variations in STC transport, where it moderates, or even dominates, tropical interannual variability. This modulation is in turn transmitted back to midlatitudes

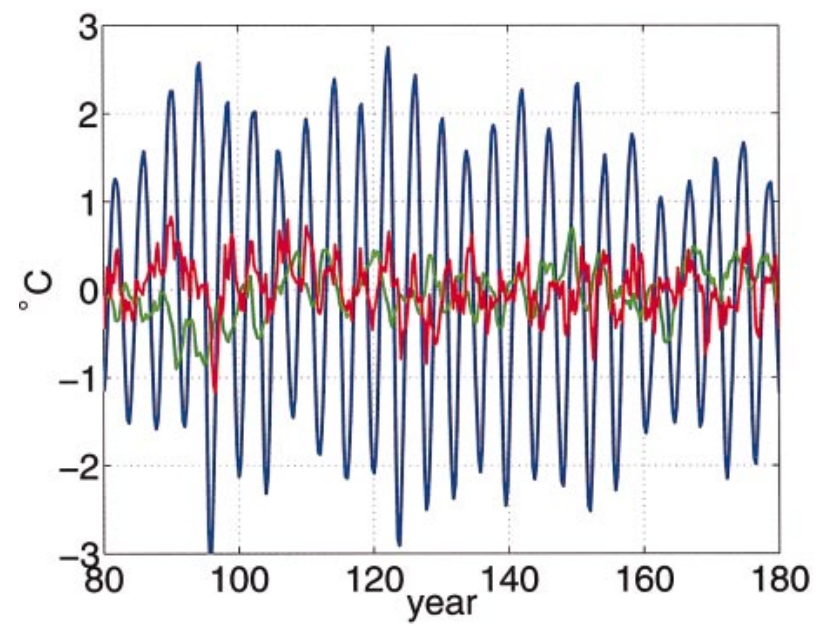

FIG. 15. Time series of $\mathcal{T}_{1}$ (blue), and temperature anomalies in regions $\mathrm{W}$ (green) and $\mathrm{E}$ (red) in the coupled run with a self-sustained interannual $\left(\phi_{1}=1.3\right)$ and stochastic forcing, but no decadal mode $\left(\phi_{o}=0\right)$. Units are $1{ }^{\circ} \mathrm{C}$.

via atmospheric connections, where it has the proper phasing to modify the self-sustained decadal signal or to reinforce a damped one. Extratropical stochastic forcing weakens the amplitude of the decadal mode, allowing the interannual mode to dominate in the Tropics as it should.

\section{Summary and discussion}

We have explored the causes of PDV and EDV in an intermediate coupled ocean-atmosphere model of the Pacific region. Its ocean component is a variable-temperature, $3^{1} \frac{1}{2}$-layer model (Fig. 1). Its atmospheric component consists of three parts: an empirical model that utilizes SVDs between observed wind and SST anomalies to determine $\Delta \boldsymbol{\tau}$ from the model $\Delta T_{1}$ field [Eqs. (7) and (8)]; a simple representation of the planetary boundary layer that determines $\Delta Q$ [section 2c(2)]; and a prescribed stochastic wind stress forcing $\Delta \boldsymbol{\tau}^{\prime}$ [Eq. (17)]. The structure functions, $\phi_{k}$ and $\theta_{k}$, included in (7) and (8), are an integral part of the empirical model. They specify regions $1\left(\theta_{k} \neq 0\right)$ and $2\left(\theta_{k}=0\right)$ where ocean-to-atmosphere coupling is active and absent, and thereby allow a model definition of atmosphere teleconnections (i.e., an atmospheric response in region 2 generated in region 1). For dynamical simplicity, only SVD1, SVD3, and SVD4 are used, since solutions to atmospheric GCMs suggest that their SST and wind stress patterns are dynamically, as well as statistically, linked [section 2c(1)i]. SVD2 is not used because it closely resembles SVD2', the corresponding SST-tendency SVD [section 2c(1)ii], and hence is likely to be determined mostly by atmosphere-to-ocean forcing. SVD1 and SVD3 are essential for generating the interannual and decadal modes, respectively.

Simultaneous cross correlations between SST and at- 
mospheric variables can result from prior forcing by atmospheric noise (Frankignoul 1985, 1999). Thus, the patterns in our SVDs could result entirely from atmosphere-to-ocean forcing, potentially a fundamental inconsistency in the formulation of our empirical atmosphere (section 2c(1)ii]. The similarity of our monthly mean and 7-month averaged SVDs, however, shows that the former captures patterns that can persist for up to 7 months and vary interannually. We conclude that the possibility that ocean-to-atmosphere processes are involved in their structure cannot be ruled out. Moreover, cross correlations of time series associated with wintertime SVD3s suggest that they are associated with decadal variability not just high-frequency noise, although this result lacks statistical significance. We also explored the use of lag-1 SVDs as a means for weakening atmosphere-to-ocean forcing, but concluded that lagging the fields aliased high-frequency variability into the structure of SVD3 and SVD4.

Solutions are able to develop two modes of oscillation, namely, interannual and decadal modes with periods close to 4 and 12 yr. The interannual mode is isolated by including only SVD1 in the statistical atmosphere, that is, by setting $N=1$ in (7). The resulting solution develops an interannual oscillation that resembles ENSO, including atmospheric teleconnections to midlatitudes. Consistent with the time-delay oscillator theory of ENSO in a self-sustaining regime, off-equatorial Rossby waves reflect from the western boundary as equatorial Kelvin waves, weakening $\left|\Delta T_{1}\right|$ in the eastern ocean, and thereby triggering the onset and termination of warm and cold events.

The decadal oscillation is isolated by excluding SVD1 from the statistical atmosphere, by starting the summation in (7) at $k=3$. For the parameter choices listed in section 2c, solutions develop a self-sustained decadal mode, which at midlatitudes has a structure similar to the Latif and Barnett (1994) mode. Our analyses suggest that a midlatitude time-delay oscillator is responsible for this mode, with positive feedback present in both the northwest midlatitudes and northeast subtropics and delayed negative feedback occurring via Rossby wave propagation.

To illustrate the cool phase of the decadal cycle, suppose initially that a cool $\Delta T_{1}$ appears in the northwest Pacific. This anomaly drives atmospheric teleconnections that modify $\boldsymbol{\tau}$ in the northeast Pacific, creating an anticyclone there $\left(\theta=0^{\circ}\right.$ and $45^{\circ}$, Figs. $6 a$ and $6 \mathrm{~b}$, respectively). The southern part of the anticyclone acts to strengthen the northeast trades, cooling $T_{1}$ by latent heat changes driven by wind speed changes. This cooling in turn strengthens the anticyclone, extending it southward through its projection onto primarily SVD3 $\left(\theta=90^{\circ}\right.$ and $135^{\circ}$, Figs. $6 \mathrm{a}$ and $6 \mathrm{~b}$, respectively). Delayed negative feedback results from changes in oceanic circulation forced by the anticyclone and the subsequent propagation of oceanic Rossby waves across the basin (Fig. 5). The arrival of these waves in the northwest
Pacific triggers a switch in $\Delta T_{1}$ to a warm phase, which is maintained through advection and convective overturning.

The potential importance of coupling in the northwest midlatitudes has been noted by others (Xie et al. 2000; Miller and Schneider 2000), and interpreted as an influence of SST anomalies there on the location of the storm track (Nakamura and Izumi 2002; Yulaeva et al. 2001). The importance of interactions in the northeast subtropics has also been reported. For example, the atmospheric forcing of SST anomalies in the northeast subtropics has been demonstrated in a number of studies (Barnett et al. 1999; Pierce et al. 2000b, among others). Very recently, it has been shown that the response of an atmospheric GCM to an SST anomaly imposed in the northeast subtropics is a cyclone located northwest of the anomaly that enhances the initial perturbation through latent heat and shortwave fluxes (F.-F. Jin 2001, personal communication), similar to our coupled solution.

For smaller values of coupling $\left(\phi_{o}=1.2\right)$, the decadal mode is no longer self-sustained, and the decadal response of the system reduces to that of a weakly nonlinear, damped oscillator. Stochastic forcing by a wind stress anomaly $\Delta \boldsymbol{\tau}^{\prime}$ [section $2 \mathrm{c}(3)$ ] is unable to maintain the decadal mode or to generate a spectral peak at decadal timescales (section 4c). On the other hand, the decadal signal can be maintained when tropical coupling is included $\left(\phi_{1}=1.3\right)$ through atmospheric teleconnections from the Tropics (section 5).

Model EDV is linked to PDV by variations in the transport of the North Pacific STC (section 4b). According to (11c), these transport variations arise necessarily via changes in wind stress forcing north of $12^{\circ} \mathrm{N}$. Additional tests reported in section $4 \mathrm{~b}$ indicate that the equatorial response is forced primarily by winds south of $28^{\circ} \mathrm{N}$, and moreover that wind variability along $y_{d}=18^{\circ} \mathrm{N}$ is particularly important. In response to easterly wind anomalies along $y_{d}$, for example, more warm surface water diverges from the tropical ocean. After a period of adjustment (about $2 \mathrm{yr}$ ), more cool water upwells in the eastern Pacific to supply water for the surface divergence and the cold tongue strengthens, which in turn helps to maintain the easterly anomalies. This strengthened cold tongue modifies the tropical oceanatmosphere coupling that generates the model ENSO (section 5). In the real ocean, a strengthened cold tongue prevents atmospheric convection in the western Pacific from shifting as far eastward, thereby decreasing the amplitude or likelihood of ENSO warm events. Note that this mechanism is not the one hypothesized by $\mathrm{Gu}$ and Philander (1997), since it is transport rather than temperature that varies; indeed, variations in equatorial $T_{2}$ are too small to account for $\mathcal{T}_{1}$. Extratropical stochastic forcing also affects EDV through its effect on the STC transport, producing more pronounced decadal variability when there is an active decadal mode (Fig. 14) than when there is not (Fig. 15). 
In conclusion, our intermediate model provides a useful step in the hierarchy of coupled systems that is necessary to understand the causes of PDV and EDV. Among other things, it identifies potential key regions of ocean-to-atmosphere interaction (i.e., the northwest midlatitudes and northeast subtropics) and demonstrates the capability of STC transport variability for generating EDV. On the other hand, the model's dynamical simplicity is also a limitation, as it neglects a number of potentially important processes. These processes include the lack of a seasonal cycle, the ocean model's simplistic mixed-layer physics [Eqs. (2a) and (2b)], and the lack of a time-varying Indonesian Throughflow, which can affect how much of the STC variability actually reaches the equator. Perhaps most serious is the statistical nature of the model atmosphere. As a logical next step in model development, we plan to replace the statistical atmosphere with one that is both dynamically based and computationally efficient.

Acknowledgments. We thank Axel Timmermann and Fei-Fei Jin for helpful discussions. This research was supported by NOAA through Grant NA76GP0353 and by the Frontier Research System for Global Change through its sponsorship of the International Pacific Research Program (IPRC).

\section{REFERENCES}

Alexander, M. A., 1992: Midlatitude atmosphere-ocean interaction during El Niño. Part I: The North Pacific Ocean. J. Climate, 5, 944-958.

Barnett, T. P., and M. Latif, 1999: Reply. J. Climate, 12, 1873.

—, and — 2000: Corrigendum. J. Climate, 13, 511

_ D. W. Pierce, R. Saravanan, N. Schneider, D. Dommenget, and M. Latif, 1999: Origins of the midlatitude Pacific decadal variability. Geophys. Res. Lett., 26, 1453-1456.

Barsugli, J. J., and D. S. Battisti, 1998: The basic effects of atmosphere-ocean thermal coupling on midlatitude variability. J. Atmos. Res., 55, 477-493.

Bladé, I., 1997: The influence of midlatitude ocean-atmosphere coupling on the low-frequency variability of a GCM. Part I: No tropical SST forcing. J. Climate, 10, 2087-2106.

Blanke, B., and S. Raynaud, 1997: Kinematics of the Pacific Equatorial Undercurrent: An Eulerian and Lagrangian approach from GCM results. J. Phys. Oceanogr., 27, 1038-1053.

Bretherton, C. S., C. Smith, and J. M. Wallace, 1992: An intercomparison of methods for finding coupled patterns in climate data. J. Climate, 5, 541-560.

Bryan, K., 1991: Poleward heat transport in the ocean. Tellus, 43, $104-115$.

da Silva, A. M., C. C. Young, and S. Levitus, 1994a: Algorithms and Procedures. Vol. 1, Atlas of Surface Marine Data 1994, NOAA Atlas NESDIS 6, $83 \mathrm{pp}$.

$[, \ldots$, and —_, 1994b: Anomalies of Heat and Momentum Fluxes. Vol. 3, Atlas of Surface Marine Data 1994, NOAA Atlas NESDIS 8, $413 \mathrm{pp}$.

Davis, R. E., 1976: Predictability of sea surface temperature and sea level pressure anomalies over the North Pacific Ocean. J. Phys. Oceanogr., 6, 249-266.

Deser, C., and M. L. Blackmon, 1995: On the relationship between tropical and North Pacific sea surface temperature variations. $J$. Climate, 8, 1677-1680.

_, and M. S. Timlin, 1997: Atmosphere-ocean interaction on weekly timescales in the North Atlantic and Pacific. J. Climate, 10, 393-408.

— M. A. Alexander, and M. S. Timlin, 1996: Upper-ocean thermal variations in the North Pacific during 1970-1991. J. Climate, 9, $1840-1855$.

$\ldots, \ldots$, and $—$ 1999: Evidence for a wind-driven intensification of the Kuroshio Current Extension from the 1970s to the 1980s. J. Climate, 12, 1697-1706.

Frankignoul, C., 1985: Sea surface temperature anomalies, planetary waves and air-sea feedback in the middle latitudes. Rev. Geophys., 23, 357-390.

_ 1999: A cautionary note on the use of statistical atmospheric models in the middle latitudes: Comments on "Decadal variability in the North Pacific as simulated by a hybrid coupled model." J. Climate, 12, 1871-1872.

Gu, D., and S. G. H. Philander, 1997: Interdecadal climate fluctuations that depend on exchanges between the Tropics and the Extratropics. Science, 275, 805-807.

Harrison, D. E., 1989: On climatological monthly mean wind stress and wind stress curl fields over the world ocean. J. Climate, 2, $57-70$.

Hasselmann, K., 1976: Stochastic climate models. 1. Theory. Tellus, 28, 473-485.

Hellerman, S., and M. Rosenstein, 1983: Normal monthly wind stress over the world ocean with error estimates. J. Phys. Oceanogr., 13, 1093-1104.

Ji, M., A. Leetmaa, and V. E. Kousky, 1996: Coupled model predictions of ENSO during the 1980s and the 1990s at the National Centers for Environmental Prediction. J. Climate, 9, 3105-3120

Kleeman, R., and S. B. Power, 1995: A simple atmospheric model of surface heat flux for use in ocean modeling studies. J. Phys. Oceanogr., 25, 92-105.

—, and —_, 1999: Modulation of ENSO variability on decadal and longer timescales. El Niño and the Southern Oscillation, Multiscale Variability and Its Impacts on Ecosystems and Society, H. F. Diaz and V. Markgraf, Eds., Cambridge University Press, 413-442.

— J. J. McCreary, and B. A. Klinger, 1999: A mechanism for the decadal variation of ENSO. Geophys. Res. Lett., 26, 1743-1747.

Klinger, B. A., J. P. McCreary, and R. Kleeman, 2002: The relationship between oscillating subtropical wind stress and equatorial temperature. J. Phys. Oceanogr., 32, 1507-1521.

Knutson, T. R., and S. Manabe, 1998: Model assessment of decadal variability and trends in the tropical Pacific Ocean. J. Climate, 11, 2273-2296.

Kraus, E. B., and J. S. Turner, 1967: A one-dimensional model of the seasonal thermocline. II. The general theory and its consequences. Tellus, 19, 98-106.

Large, W. G., and S. Pond, 1981: Open ocean momentum flux measurements in moderate to strong winds. J. Phys. Oceanogr., 11, 324-336.

— , and — 1982: Sensible and latent heat flux measurements over the ocean. J. Phys. Oceanogr., 12, 464-482.

Latif, M., and T. P. Barnett, 1994: Causes of decadal climate variability over the North Pacific and North America. Science, 266, 634-637.

_ and — 1996: Decadal climate variability over the North Pacific and North America: Dynamics and predictability. J. Climate, 9, 2407-2423

— , R. Kleeman, and C. Eckert, 1997: Greenhouse warming, decadal variability, or El Niño? An attempt to understand the anomalous 1990s. J. Climate, 10, 2221-2239.

Lau, N.-C., and M. J. Nath, 1996: The role of the "atmospheric bridge" in linking tropical Pacific ENSO events to extratropical SST anomalies. J. Climate, 9, 2036-2057.

Liu, Z. Y., S. G. H. Philander, and P. C. Pacanowski, 1994: A GCM study of tropical-subtropical upper-ocean water exchange. $J$. Phys. Oceanogr., 24, 2606-2623.

Lu, P., J. P. McCreary, and B. A. Klinger, 1998: Meridional circulation 
cells and the source waters of the Pacific equatorial undercurrent. J. Phys. Oceanogr., 28, 62-84.

Lysne, J., P. Chang, and B. Giese, 1997: Impact of the extratropical Pacific on equatorial variability. Geophys. Res. Lett., 24, 25892592.

McCreary, J. P., and P. K. Kundu, 1988: A numerical investigation of the Somali Current during the Southwest Monsoon. J. Mar. Res., 46, 25-58.

_ _ and P. Lu, 1994: On the interaction between the subtropical and the equatorial oceans: The subtropical cell. J. Phys. Oceanogr., 24, 466-497.

McPhaden, M., and D. Zhang, 2002: Slowdown of the meridional overturning circulation in the upper North Pacific. Nature, 415, 603-608.

Miller, A. J., and N. Schneider, 2000: Interdecadal climate regime dynamics in the North Pacific Ocean: Theories, observations and ecosystem impacts. Progress in Oceanography, Vol. 47, Pergamon, 355-379.

Moore, A. M., 1999: Wind-induced variability of ocean gyres. Dyn. Atmos. Oceans, 29, 335-364.

Muennich, M., M. Latif, S. Venzke, and E. Maier-Reimer, 1998: Decadal oscillations in a simple coupled model. J. Climate, 11, $3309-3319$.

Nakamura, H., and T. Yamagata, 1999: Recent decadal SST variability in the northwestern Pacific associated atmospheric anomalies. Beyond El Niño: Decadal and Interdecadal Climate Variability, A. Navarra, Ed., Springer-Verlag, 49-72.

— cently observed in the Pacific storm track activity and East Asian winter monsoon. J. Climate, 15, 1855-1874.

_ , G. Lin, and T. Yamagata, 1997: Decadal climate variability in the North Pacific during the recent decades. Bull. Amer. Meteor. Soc., 78, 2215-2225.

Neelin, J. D., and W. Weng, 1999: Analytical prototypes for oceanatmosphere interaction at midlatitudes. Part I: Coupled feedbacks as a sea surface temperature dependent stochastic process. $J$. Climate, 12, 697-721.

Nitta, T., and S. Yamada, 1989: Recent warming of recent sea surface temperature and its relation to Northern Hemisphere circulation. J. Meteor. Soc. Japan, 67, 375-382.

Nonaka, M., and S.-P. Xie, 2003: Covariations of sea surface temperature and wind over the Kuroshio and its extension: Evidence for oceanic-atmospheric feedback. J. Climate, in press.

— - — , and K. Takeuchi, 2000: Equatorward spreading of a passive tracer with application to North Pacific interdecadal temperature variations. J. Oceanogr., 56, 173-183.

—_ — , and J. McCreary, 2002: Decadal variations in the subtropical cells and equatorial Pacific SST. Geophys. Res. Lett., 29, doi: 10.1029/2001GL013717.

Parker, D. E., C. K. Folland, A. Bevan, M. N. Ward, M. Jackson, and K. Maskell, 1994: Marine surface data for analysis of climatic fluctuations on interannual to century time scales. Natural
Climate Variability on Decade-To-Century Time Scales, D. G. Martinson et al., Eds., National Academy Press, 241-251.

Pierce, D. W., T. P. Barnett, and M. Latif, 2000a: Connections between the Pacific Ocean Tropics and midlatitudes on decadal timescales. J. Climate, 13, 1173-1194.

_ - _ N. N. Schneider, R. Saravanan, D. Dommenget, and M. Latif, 2000b: The role of ocean dynamics in producing decadal climate variability in the North Pacific. Climate Dyn., 18, 5170.

Reynolds, R. W., and T. M. Smith, 1994: Improved global sea surface temperature analyses using optimum interpolation. J. Climate, 7, 929-948.

Rothstein, L. M., R.-H. Zhang, A. J. Busalacchi, and D. Chen, 1998 A numerical simulation of the mean water pathways in the subtropical and tropical Pacific Ocean. J. Phys. Oceanogr., 28, 322 344.

Saravanan, R., and J. C. McWilliams, 1997: Stochasticity and spatial resonance in interdecadal climate fluctuations. J. Climate, 10, 2299-2320.

Schneider, N. S., and A. J. Miller, 2001: Predicting western North Pacific Ocean climate. J. Climate, 14, 3997-4002.

,-- M. A. Alexander, and C. Deser, 1999: Subduction of decadal North Pacific temperature anomalies: Observations and dynamics. J. Phys. Oceanogr., 29, 1056-1070.

,,$\ldots$, and D. W. Pierce, 2002: Anatomy of North Pacific decadal variability. J. Climate, 15, 586-605.

Thompson, C. J., and D. S. Battisti, 2000: A linear stochastic dynamical model of ENSO. Part I: Model development. J. Climate, 13, 2818-2832.

Timmermann, A., and F.-F. Jin, 2002: A nonlinear mechanism for decadal El Niño amplitude changes. Geophys. Res. Lett., 29, doi: 10.1029/2001GL013369.

Trenberth, K. E., 1990: Recent observed interdecadal climate changes in the Northern Hemisphere. Bull. Amer. Meteor. Soc., 71, 988993.

Wallace, J. M., C. Smith, and Q. Jiang, 1990: Spatial patterns of atmosphere-ocean interaction in the northern winter. J. Climate, 3, 990-998.

Wang, B., 1995: Interdecadal changes in El Niño onset in the last four decades. J. Climate, 8, 267-285.

Weng, W., and J. D. Neelin, 1999: Analytical prototypes for oceanatmosphere interaction at midlatitudes. Part II: Mechanisms for coupled gyre modes. J. Climate, 12, 2757-2774.

Xie, S.-P., T. Kunitani, A. Kubokawa, M. Nonaka, and S. Hosoda, 2000: Interdecadal thermocline variability in the North Pacific for 1958-97: A GCM simulation. J. Phys. Oceanogr., 30, 2798 2813.

Yukimoto, S., M. Endoh, Y. Kitamura, A. Kitoh, T. Motoi, and A. Noda, 2000: ENSO-like interdecadal variability in the Pacific Ocean as simulated in a coupled general circulation model. $J$. Geophys. Res., 105, 13 945-13 963.

Yulaeva, E., N. Schneider, D. W. Pierce, and T. P. Barnett, 2001: Modeling of North Pacific climate variability forced by oceanic heat flux anomalies. J. Climate, 14, 4027-4046. 